
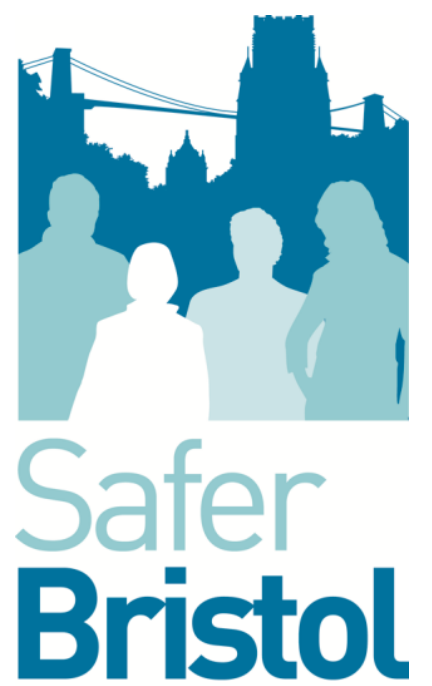

Crime, Drugs and Alcohol Partnership

\title{
Crime and Disorder Strategic Assessment
}

\section{3}

Author:

Nasrul Ismail

Partnership Analyst

Avon \& Somerset Constabulary and Safer Bristol 


\section{Table of Contents}

\begin{tabular}{|cc}
\hline Content & Page \\
\hline 1. Executive Summary & 3 \\
\hline 2. Aims and Methodology & 5 \\
\hline 3. Horizon Scanning & 7 \\
\hline 4. Overview of Crime and Community Confidence & 15 \\
\hline 5. Acquisitive Crime & 18 \\
\hline 6. Violent Crime & 24 \\
\hline 7. Domestic Violence and Abuse & 28 \\
\hline 8. Sexual Violence & 35 \\
\hline 9. Human Trafficking & 39 \\
\hline 10. Anti-social Behaviour & 42 \\
\hline 11. Hate Crime & 47 \\
\hline 12. Prevent & 54 \\
\hline 13. Reducing Re-offending & 55 \\
\hline 14. Glossary of Terms & 58 \\
15. Bibliography & 60 \\
\hline
\end{tabular}




\section{Executive Summary}

This Executive Summary highlights some of the key areas of focus for the Partnership over the coming year. Each individual section within the assessment provides a more thorough picture of each crime type and includes a number of recommendations.

1. The Crime \& Disorder Strategic Assessment draws on a range of information sources to provide an overview of the current and future crime, disorder and community safety issues affecting Bristol. As Bristol accounts for $41 \%$ of all crime in Avon \& Somerset, the Strategic Assessment feeds directly into the Police and Crime Commissioner (PCC) Crime Needs Assessment.

2. During $2012 / 2013$, Bristol had undergone a series of significant organisational changes including the elected Mayor, the Police and Crime Commissioner (PCC) and the appointment of a new Chief Constable. Further changes are on the horizon and those that impact on crime and community safety have been considered in more detail.

3. The needs of Bristol's residents have also changed. Increases to the Black and Minority Ethnic (BME) population and the fact that students now make up $8.3 \%$ of the total population are both important considerations which present challenges in terms of potential community tensions and risk of victimisation.

4. Patterns of drug use have a considerable impact on community safety, and alcohol misuse remains a significant challenge within the city. Areas to be aware of include reductions in opiate and/or crack use, increases in 'legal highs' and the government's decision to classify Khat as a Class C drug.

5. Bristol is committed to becoming a restorative city, where restorative approaches are used to tackle conflict in the community, in schools and in the work place. The use of restorative approaches has been considered within each thematic area of the Strategic Assessment.

6. Total crime numbers are at the lowest they have been in 12 years. This reduction has mainly been in theft from vehicles, criminal damage to vehicle and criminal damage to dwellings. Public perceptions of crime have also improved with $71 \%$ of Avon and Somerset residents reporting confidence in their local Police force ${ }^{1}$.

7. Acquisitive crime ${ }^{2}$ accounts for almost half of the total recorded crime in Bristol. There have been noted decreases in vehicle crime and domestic burglary since 2006 but shoplifting has increased. The IMPACT multi-agency team is working effectively with repeat offenders to address issues including problematic drug/alcohol use, homelessness, learning disabilities and mental health problems. Targeted activity has taken place to address the specific needs of different victims of acquisitive crime. For example, the Safer Homes Scheme visited $93 \%$ of burglary victims to reduce repeat burglary rates, the Police have been working with Bristol's Asian communities in relation to a spate of burglaries targeting gold, and Police data on the victims of theft has been reviewed to provide a detailed understanding of mobile phone theft.

8. Just under $40 \%$ of Avon and Somerset Police recorded violent crime occurs in Bristol. In 2012/2013, the rate of violence against the person declined by $19 \%$. The known links between night time economy and violent crime have been the focus of prevention activity in this area, together with schemes such as Gold Standard Taxi Driver and Purple Flag Award status, in which Bristol is recognised as a well-managed and vibrant place to visit.

9. Under-reporting is a cross-cutting issue, and is particularly pertinent within the areas of hate crime, domestic violence and sexual offences. More work needs to be done to increase awareness of these issues to instil confidence so that victims do come forward and increase the opportunities for third party reporting.

10. With a number of offender management programmes in place, such as Troubled Families, IRiS and IMPACT, the Strategic Assessment recommends cross matching the perpetrators of hate crime and domestic violence and abuse against these cohort of offenders to jointly target approaches.

\footnotetext{
${ }^{1}$ Crime Survey for England and Wales (December 2012).

2 'Acquisitive Crime' is defined as offences where the offender derives material gain from the crime
} 
11. There has been a reduction in the number of domestic violence and abuse incidents reported to the Police, $81 \%$ of the victims reporting were female and $43 \%$ of incidents had children linked to the domestic violence and abuse cases.

A key recommendation is to undertake an in-depth needs analysis into the extent of domestic violence and abuse in Bristol, including a review of referral thresholds and accessibility of services. Safer Bristol intends to start the process of recommissioning a number of domestic violence and abuse support services agencies in 2013 so it is essential that the level of need is clearly identified.

12. The Strategic Assessment has highlighted local and national intelligence gaps that Bristol is working on addressing, which include Female Genital Mutilation (FGM), Human Trafficking and Terrorism and Violent Extremism. Positive action is being taken to raise staff awareness of human trafficking as well as safe and effective ways of combating it. A process called 'Channel' has been developed to support people at risk of being drawn towards terrorism and violent extremism.

13. The most significant types of anti-social behaviour (ASB) in Bristol are disturbance and nuisance, harassment and threats, assault, and domestic disturbance or violence. Together these account for $88 \%$ of ASB reported to the City's authorities (Avon \& Somerset Police, Bristol City Council and Avon Fire \& Rescue). The Troubled Families Scheme works with repeat offenders. There are 1,355 families that have been identified as part of the scheme who will be worked with for the next three years.

14. Among the core cities in England, Bristol has the second highest rate of reported crime for racially or religiously aggravated offences per thousand population in 2012/2013. Safer Bristol has recently awarded grant funding to services to deliver a hate crime support service across Bristol, to victims of race hate, disablist, homophobic, age and gender related incidents and crimes. The use of restorative approaches in hate crime incidents is being developed for younger perpetrators and repeat offenders.

15. Caseloads supervised by the Youth Offending Team have reduced over the past four years but the seriousness of the caseload has increased, particularly in relation to complex needs, vulnerability and risks that the young offenders pose to themselves. The number of serious cases in relation to safeguarding issues has trebled since 2011 and there has been a sharp increase in the numbers of girls and young women in the youth justice system locally. Resources need to be available to meet the demographic challenge and the likely increased demands on the system. 


\section{Aims and Methodology}

The Crime \& Disorder Strategic Assessment is a public document that seeks to provide the direction for Safer Bristol Partnership. It provides an overview of the current and future crime, disorder, and community safety issues affecting Bristol.

The Strategic Assessment is also produced by Safer Bristol to meet its statutory obligation ${ }^{3}$ to provide:

- An accurate understanding of the current situation

- An evaluation of how the situation is presently changing

- Predictions about how the situation will change in the future

The understanding, evaluation, and predictions will enable Safer Bristol and its partner organisations to:

- Identify the current, emerging, and future opportunities and challenges

- Assess the impact these will have on our communities

- Make informed decisions on partnership enforcement activities and resource requirements

- Set strategic priorities for the partnership for 2013/2014

- Influence the production of the Crime Needs Assessment produced by the Office of the Police and Crime Commissioner (PCC).

\section{Structure of the Strategic Assessment}

The Strategic Assessment is structured based on the following themes:

- Acquisitive crime

- Violent crime

- Domestic violence and abuse

- Sexual violence

- Human trafficking

- Anti-social behaviour

- Hate crime

- Prevent

- Reducing re-offending

Each of the themes above will be accompanied with:

- A review of performance

- A profile of victim, offender, and location, with a consideration of re-offending, repeat victimisation, substance misuse, and youth offending

- Recommendations for the partnership

\section{Information Sources}

The Strategic Assessment will take into account research, evidence, and intelligence from national and local sources, and will draw on the professional expertise of those working locally, particularly from the following sources:

- Avon and Somerset Police

- Bristol City Council (including Public Health)

- Avon Fire Service

- Avon and Somerset Probation Trust

- National Treatment Agency

- Ministry of Justice

- Home Office

- Quality of Life Survey

- British Crime Survey

${ }^{3}$ Section 7 of the Crime \& Disorder (Formulation \& Implementation of Strategy) Regulations 2007; Statutory Instrument (SI) Number 1830. 
- Youth Offending Team (YOT)

- Office of the Police and Crime Commissioner

- Non-statutory partner agencies

Core city comparison data will be used, where available, to compare crime rates in Bristol with other core cities in England such as Birmingham, Newcastle, Sheffield, Leeds, Liverpool, Nottingham, and Manchester. 


\section{Horizon Scanning}

\section{Bristol's Demographics}

The population of Bristol is estimated to be $432,500 .{ }^{4}$ Bristol is the seventh largest city in England outside of London. The 2011 Census has highlighted a number of changes to the profile of Bristol's residents which need to be considered when reviewing the crime and disorder in the city.

Ethnicity: Bristol has a diverse population. The Black and Minority Ethnic (BME) population in Bristol has increased from $8.2 \%$ to $16 \%$ of the total population. The largest growth since 2001 has been in White Other (includes Eastern Europeans), Black African, Black Other and mixed ethnic groups. The Somali population has also increased in Bristol over recent years to over $3,000^{5}$. At least 91 languages are spoken in Bristol. Polish is the main language spoken after English followed by Somali. 34,989 (9\%) of people do not speak English as their main language and of these 6,089 (1.5\% of all people) cannot speak English or cannot speak English very well. 201 people living in Bristol use sign language as their main language.

The estimated flow of international migrants to Bristol up to $30^{\text {th }}$ June 2012 was 5,100 and the estimated outflow for the same period was 4,600 . This net migration of just over 500 was considerably lower than at any other time in the past.

Consideration needs to be given to the additional risk of victimisation for specific crime types and opportunity for community tension are challenges that we face.

Religion and Belief: There are at least 45 religions represented in Bristol. The largest religion is Christian (47\%, 200,254 people), although following national trends the proportion of people stating that they are Christian has fallen from $62 \%$ of all people living in Bristol in 2001. Bristol is ranked $7^{\text {th }}$ in England and Wales for the proportion of people stating that they have no religion (37\%, 160,218 people). This is up from $25 \%$ in 2001 . Since 2001 the religion that increased the most in Bristol has been the Muslim religion, which increased from 2\% of all people in Bristol in 2001 to $5 \%(22,016)$ of all people in $2011^{6}$.

Age: Bristol has a relatively young age profile with more children than people aged 65 and over. The median age of people living in Bristol is 33.7 years old. This compares to the England and Wales median of 39 years, on the Census Day. This appears to be related to the fact that the number of full time students aged 18 and over living in Bristol during the term has increased from 25,573 to 35,638 . Students now make up $8.3 \%$ of the total population of Bristol. The rise of young professionals and students within the city may impact on the types of crime committed and places additional demands within the night time economy.

Aside from the student population, there are also higher projected growth rates amongst children aged 5 to 14 . This is particularly relevant given that research has found young people to be at a disproportionately high risk of becoming both victims and offenders. ${ }^{7}$ There are higher projected growth rates amongst people aged 70 and over which may present new challenges in terms of safeguarding and vulnerability to specific low volume but high impact crimes such as distraction burglary.

Sexual Orientation: The government estimates that $5-7 \%$ of the population are lesbian, gay and bisexual, which would mean that of the 432,500 people estimated to be living in Bristol, 25,680 may be from this group. The Census does not include a question about sexual orientation but the Bristol Quality of Life survey does. ${ }^{8}$.

Disability: In terms of long-term illness or disability affecting day-to-day activities, $16.7 \%$ of the population considered themselves under this category.

Mental Health: People living with mental health conditions and the costs of treating them are projected to increase steadily over the next 20 years $^{9}$. Studies indicate higher prevalence of mental health issues among the homeless, victims of domestic violence and abuse, offenders, children of offenders and the prison population in particular.

\footnotetext{
${ }^{4}$ Bristol City Council, '2011 Census First Release - Bristol City Council Analysis', available at:

http://www.bristol.gov.uk/sites/default/files/documents/council and democracy/statistics and census information/2011\%20Census\%20First\%2 0Release\%20-\%20Bristol\%20City\%20Council\%20Analysis.pdf (last accessed: 11 ${ }^{\text {th }}$ July 2013).

5 In Census 2011, 2,950 people described their ethnic origin as Somali, while 4,981 people stated that they were born in Somalia

${ }^{6}$ Bristol Community Cohesion Statistics (June 2013).

${ }^{7}$ Avon and Somerset Police and Crime Commissioners Needs Assessment (2013).

${ }^{8} \mathrm{~A}$ maximum of 89 LGBT respondents answered the Quality of Life Survey 2012.

${ }_{9}$ Dementia cases are expected to increase by $23 \%$ for females and 43\% for males between 2010 and 2025, Bristol Joint Strategic Needs Assessment (2012).
} 
Increased prevalence of mental health issues may lead to increased vulnerability to discrimination and increased demand on safeguarding and agency requirements for places of safety provision.

\section{Deprivation}

Areas of Bristol are amongst some of the most deprived in the country. The contrast is noticeable, as deprived areas often are adjacent to some of the least deprived areas in the country. This is noteworthy as the links between living in a deprived area and risk of victimisation and susceptibility to offending are well established.

Bristol has 32 Lower Super Output Areas (LSOAs) ${ }^{10}$ in the most deprived 10\% in England for multiple deprivation (compared to 39 in 2007 and 35 for 2004). Of these 32 LSOAs there are 14 in the most deprived (5\%) and one in the most deprived (1\%, Lawrence Hill). The number of people living in the most deprived $10 \%$ of LSOAs is 60,665 people, which is $14 \%$ of all residents living in Bristol.

At a national level 26 of Bristol LSOAs are in the most income deprived areas nationally, of these 11 are in south Bristol, 8 are in the central area and seven in north and east Bristol. On a ward basis, more than a third of people are income deprived in Lawrence Hill (36\%) and Filwood (35\%). The whole of Lawrence Hill ward falls within the most deprived $10 \%$ of areas in England with the exception of Redcliffe.

\section{Organisational Change}

\section{Bristol's Elected Mayor}

Bristol's Elected Mayor George Ferguson came into post in November 2012. As the elected leader of Bristol the Mayor represents the interests of Bristol's citizens and leads the city council and its full range of services - with a turnover of around £1billion a year. The role of elected Mayor replaced the previous role of Council Leader.

\section{Police and Crime Commissioner (PCC)}

Sue Mountstevens was elected as the first Police and Crime Commissioner for Avon and Somerset in November 2012, to represent the local citizens' voice and ensure that the policing activities meet the community needs.

The first Police and Crime Plan sets out the vision for policing and community safety across Avon and Somerset for the next four years. The following four priority areas have been identified:

- Tackle anti-social behaviour

- Tackle violent crime, particularly against women and children

- Prevent and reduce burglaries and the fear of burglaries

- Ensure victims are at the heart of the criminal justice system

As Bristol accounts for $41 \%$ of all crime in Avon \& Somerset the Safer Bristol Partnership has a key role to play in addressing these objectives. This Strategic Assessment will make reference to the PCC priorities throughout.

\section{Police Chief Constable Appointed}

Following on from the PCC appointment, Nick Gargan was appointed as the new Chief Constable and took up his office on $1^{\text {st }}$ March 2013. This year also saw considerable change in Association of Chief Police Officers personnel, with a new Deputy Chief Constable, John Long, appointed in July and two new Assistant Chief Constables being appointed.

\section{Police Custody Suites}

New custody and crime investigation centres are due to open in Keynsham, Patchway and Bridgwater at the beginning of 2014. The new custody suites will support the Police's drive to bring more offenders to justice, improve services for victims and witnesses, process offenders more swiftly, and get Police officers back onto the streets as quickly as possible.

The impact of the new custody suites will be considered in the next Crime \& Disorder Strategic Assessment, especially in terms of the level of service provided regarding substance misuse, which has been re-organised to provide coverage for the whole Force area.

${ }^{10} \mathrm{LSOA}$ is defined as a small geographical area that contains around 1500 residents. 


\section{Probation Service}

The purpose of Avon and Somerset Probation is to provide the most effective management of offenders to reduce crime and to protect victims in order to increase public safety. This includes enforcing court orders, listening to and taking into account the views of victims and to rehabilitate offenders.

The Probation Service is currently undergoing an organisational transition where it will be divided into two strands a National Probation Service who will be managing serious offenders and management by a community interest company, particularly for offenders who are on licence.

\section{Geographical Focus}

Neighbourhood Partnerships have been set up to provide an opportunity for local communities to have a greater say in the way services and local issues are managed by the Council, and partner agencies. There are 14 Neighbourhood Partnerships across the City.

Neighbourhood Working began with a pilot project in Central \& East Bristol in October 2012, covering the central four Neighbourhood Partnership areas. The project brought together a 'virtual team' of officers from across the Council to respond to and address issues raised by the Neighbourhood Forums and Partnerships by a more

co-operative approach of engagement and enforcement. The pilot was successful and the feedback from council officers and residents was positive.

Since August 2013, there have been three 'Neighbourhood Working' areas - North, South and East Central. Each area has a local action plan which contains the priorities for the local area. Each Neighbourhood Partnership selects ten neighbourhood working priorities to work upon, for example community safety and environmental issues, and these are refreshed annually.

Crime Footprints containing comprehensive crime and anti-social behaviour data have been given to each Neighbourhood Delivery Team (NDT) to help inform joint tasking and partnership problem-solving processes. Each NDT has drawn up targeted action plans to specifically address the local issues identified in their footprint data. Progress against these plans will be fed back to residents and stakeholders through the Neighbourhood Partnerships.

\section{Financial Climate}

At a local and national level, an increasing number of people are facing financial challenges. There have been above average increases in 'hard pressed'11 households across Avon and Somerset.

Several reforms are likely to have an impact in relation to crime and community safety. These include reductions in disability allowance budget as part of the transition to Personal Independence Payments, introduction of the benefit cap by September 2013 and Universal Credit being phased in from October 2013. This will result in payments being made to a single member of the household and payments being made monthly. The effect could be the following: increased vulnerability to committing acquisitive crime; new opportunities for organised criminality and exploitation, including for example, increased demand in the market for stolen and counterfeit goods and reliance upon doorstep or illegal money lenders; increased family stresses and risks relating to domestic violence and abuse, and anti-social behaviour.

Within Bristol 3.6\% $(10,598)$ of the working age population were claiming Jobseeker's Allowance ${ }^{12}$ (JSA) in July 2013 which compares to $3.4 \%$ nationally. On the whole, the percentage of claimants has been decreasing since it peaked in Bristol at 4.5\% $(13,255)$ in February 2012. Focusing on the $18-24$ year age group, Bristol has a lower proportion of JSA claimants at $4.5 \%(2,585)$ compared to $6.2 \%$ nationally, although this age group does have the highest proportion of claimants. The Government's welfare reform agenda also saw the abolition of the Educational Maintenance Allowance in 2012. The potential impact may include increased vulnerability to committing low level crime and ASB among other social impacts.

With regard to young offenders, $66 \%$ out of 331 young offenders (218) received suitable education, employment and training opportunities at the end of their court order. In addition, 72 young offenders (22\%) were considered as not in education, employment or training at the end of their involvement with the YOT.

\footnotetext{
11 'Hard-pressed' is defined as experiencing great financial difficulty or distress, particularly for those with low incomes, long-term unemployment and in debt.

${ }^{12}$ Ministry of Justice, 'Legal Aid Reform': https://www.nomisweb.co.uk/reports/lmp/la/2038431894/subreports/ccadr time series/report.aspx (accessed: $20^{\text {th }}$ September 2013).
} 
Legal Aid: Changes to legal aid came into effect on $1^{\text {st }}$ April 2013 and the impact is not yet fully evident. As some cases are no longer eligible for public funds (including divorce, child contact, welfare benefits, employment, clinical negligence, and housing law), this is something that the Safer Bristol Partnership needs to be aware of as there will be inevitable consequences.

Reducing Budgets: All partners are facing significant fiscal challenges brought about by the Comprehensive Spending Review. Risks and challenges brought about by reductions in partnership budgets include:

- Dis-investment and withdrawal of agency support to the multi-agency partnerships and projects that rely on them.

- Partners retracting to their core responsibilities or providing minimum services.

- Organisational restructuring, which can have varied impacts on the scope of services and agency responsibilities within the partnership environment.

Bristol's Mayor, George Ferguson, is due to publish his three year draft budget in November 2013 for consultation. The Mayor's proposals will reflect his priorities of protecting services for the most vulnerable and addressing the city's most pressing needs as far as can be done in light of the budget constraints faced.

Avon \& Somerset Police has currently delivered £34.4 million of savings since 2011 and total savings to be delivered by 2015 is projected as $£ 44.5$ million, with further savings required depending on the level of precept set by Bristol City Council. Despite this challenge and the Police having experienced an actual reduction in staff numbers, the proportion of total workforce allocated to frontline roles is projected to increase from $79 \%$ to $81 \%$ (March $2010-$ March 2015). This is compares with an overall increase across England and Wales from $74 \%$ to $78 \%$.

Demand for social and affordable housing continues to rise and outstrip supply across Avon and Somerset. Bristol and Somerset have seen further increases in the number of people assessed as homeless or 'in priority need' since 2009, particularly young people, and the hidden homeless population is also estimated to be increasing. The Government's welfare reform agenda also extended single room rent restrictions for people under 25 years to people under 35 years in 2012 and the introduction of the under-occupancy 'bedroom tax' in 2013. Potential impact may include:

- Population or housing turnover, which may have implications for community cohesion.

- Increased vulnerability amongst young people and people under the age of 35 years, and increases in people living in houses of multiple occupancy which can create increase vulnerability to crime and ASB.

- Increases in residents in private rented accommodation may lead to an increase in landlords unwilling to take action over their ASB.

- Reduction of housing available through private landlords as opportunities retracted due to rent arrears/disputes cause landlords to retract provision for social housing.

\section{Substance Misuse}

With an estimated 4,777 opiate and/or crack users in Bristol, this equates to approximately 1 in 73 people aged over 16 years using heroin and/or crack. ${ }^{13} \mathrm{~A}$ similar picture is seen in other Core Cities. The links between drug use and crime are well recognised. Effective treatment can deliver savings in crime costs and also savings to the NHS through health improvements, reduced drug-related deaths and lower levels of blood-borne disease. A national value for money study shows that in Bristol, every $£ 1$ spent on drug treatment saves $£ 4.82$ in costs to society ${ }^{14}$ by:

- Reducing crime

- Reducing drug litter and street prostitution

- Stabilising troubled families

- Preventing drug-related deaths

- Restricting blood-borne viruses such as HIV and Hepatitis C

- Reducing the burden on the NHS

Bristol's treatment system has a good track record for engaging with opiate and/or crack users (OCUs). $72.5 \%$ of the estimated number of OCUs in Bristol were engaged with structured treatment ${ }^{15}$ during 2011/12 (3,468 of 4,777 estimated users). The most common route into treatment in 2011/12 was via the criminal justice system which accounted for $36 \%(487$ of 1,332$)$ of referrals.

\footnotetext{
${ }^{13}$ Residents in Bristol over 16 are 349,400. Therefore, 4,777 of 349,400 people in Bristol aged 16 and over are using heroin and crack is equivalent to 1 in 73 people.

${ }^{14}$ NTA, 'Drug Treatment Value for Money Tool - Summary Report' (2012).

${ }^{15}$ Structured treatment refers to appointment based treatment, not drop in or less formal treatment.
} 
Nationally, the number of clients who completed their treatment programme successfully was at its highest level during 2011/2012. This remains a priority for Bristol. During 2011/2012 there were 838 OCU exits from treatment, of which 332 were classed as successful completions (40\%). For non-opiate and/or crack users (NOCUs), there were 538 exits, of which 293 were successful completions (54\%).

Current performance in 2013/2014:16 In quarter 1 2013/2014, there were 2,854 opiate users, 551 non-opiate users and 851 alcohol users in the local treatment system. $16 \%$ of the treatment referrals came from the criminal justice system, whilst $7 \%$ of the treatment population for alcohol were referred through the same route.

The numbers of non-opiate users in treatment declined in quarter $12013 / 2014$. This was not anticipated given the increase in services for non-opiate users over the last year, and it will be monitored in the run up to the new service configuration in November 2013.

At present, between one in four and one in five of the successful completion clients returned to the treatment system within six months. The proportion of those who had successfully completed treatment and did not re-present within six months was higher than the national average for opiate users $(9.1 \%$ locally and $8.2 \%$ nationally). However, for non-opiate users, the proportion of those completing treatment who did not re-present was slightly lower than the national average ( $38.7 \%$ locally and 40.2 nationally).

A large proportion of the opiate and non-opiate clients were in treatment for less than two years $(43.9 \%$ and $94.4 \%$ respectively). For alcohol, $64.5 \%$ were in treatment for less than three months.

$44 \%$ of the clients who were using opiates at the start of treatment no longer reported using opiates by the time they had their six month review. Taking into account the profile of these clients, between $43 \%$ and $52 \%$ of opiate users were expected to stop using opiates. Therefore, Bristol is currently performing within this expected range. This is important as it could help identify individuals in treatment who are not progressing as well in treatment and help ensure that resources are focused on improving rates of abstinence.

Changes in drug use: Local, regional and national data shows a reduction in the number of new clients using opiate and/or crack presenting to drug treatment. Since April 2011 Bristol has seen an increase in the number of non-opiates from 243 users in April 2011 to 500 in March 2012. Nationally and locally there have been substantial increases in the use of recreational drugs in the night time economy and the use of Mephedrone and Ketamine. The use of 'legal' highs has continued to increase with legal highs easily accessible locally and online. New compounds are thought to be appearing on the European market at a rate of one a week. The vast majority (84\%) of young people ${ }^{17}$ in treatment services in Bristol in 2011/2012 were using a combination of cannabis, alcohol and stimulants.

Alcohol Use: The following estimates of existing drinkers in Bristol ${ }^{18}$ give an indication of the potential level of need in the local area:

- Higher risk drinkers - 19,591

- Increasing risk drinkers $-69,102$

- Dependant drinkers - 16,256

- Binge Drinkers $-61,625$

Alcohol misuse remains a significant challenge across a wide range of agencies and is a factor in a high proportion of cases of ASB and violent crime, including domestic violence and abuse. Local Alcohol Profiles for England (LAPE) 2011/2012 show alcohol-related harm to be significantly higher than the national average in Bristol, and alcoholrelated hospital admissions to be rising. In 2012/2013, the number of alcohol-related hospital admissions in Bristol was 10,450 , representing a $2 \%$ decrease compared to the previous financial year. ${ }^{19}$

Bristol's Alcohol Arrest Referral Scheme was evaluated by Home Office and found to reduce re-offending and levels of alcohol misuse. For every 100 brief alcohol interventions given, there were six less re-arrests compared to those that had no intervention. $75 \%$ success rate recorded amongst those who have been through the whole referral and detox journey with the specialist Bristol services. Results of test purchasing of underage sales of alcohol at on-licence

\footnotetext{
${ }^{16}$ NTA, 'Diagnostic Outcome Monitoring Executive Summary' (September 2013).

${ }^{17}$ Young people' is defined as 'anyone under the age of 18'.

${ }^{18}$ Local Alcohol Profiles for England (LAPE) (2013).

${ }^{19}$ Note that this is a provisional figure and subject to change.
} 
premises across Bristol will be monitored. Further information is available in the Alcohol Strategic Needs Assessment $2012 .{ }^{20}$

Commissioning Substance Misuse Services: Following an extensive commissioning process during 2011/2012, the majority of Bristol's substance misuse services (drug and alcohol) are changing to 'Recovery Orientated Alcohol and Drug Service' (ROADS). The system is built around a new model of care. It consists of phases such as engagement, change, completion, support and housing support, which aims to support drug and alcohol users to move from dependency to a stable and positive lifestyle.

The services will provide not only treatment to drug and alcohol users but also addresses other underlying problems such as homelessness, unemployment and poor physical health which can de-stabilise a drug and alcohol user while they work towards freeing themselves of their problematic use. This reflects the increased emphasis on 'recovery orientated' treatment system with a focus on achieving successful, substance-free outcomes with service users. The transition to the delivery of the new services is underway, with a proposed start of the new services by November 2013. Further detail is available in the Commissioning Strategy 2012-2015. ${ }^{21}$

Impact on Crime: People arrested for acquisitive crimes or trigger offences ${ }^{22}$ are drug tested at the Police station and if they test positive they are required to meet a criminal justice drugs worker to discuss their substance misuse and the treatment available to them. This is known as the 'Drug Intervention Programme' (DIP). During 2011/12:

- $\quad 3,114$ offenders were drug tested

- 1,151 tested positive for opiates or crack

- 1,091 clients engaged with DIP

- 695 accessed treatment services

The proportion of clients known to DIP and accessing treatment services increased in 2011/2012 to $20.6 \%$ compared to $16.4 \%$ in $2010 / 2011$.

The actual substance that offenders test positive for appears to be changing, which is indicative of changes in drug use within the wider drug using population. This is evidenced through the

Bristol's Police custody data which shows that:

- The number of arrests for trigger offences went down by $17 \%$ in $2011 / 2012$, compared to $2010 / 2011$

- The number of offenders tested positive for cocaine and opiates, and opiates only, had been consistently decreasing between 2010 and 2012

- The proportion of negative drug tests increased in 2012.

\section{Drugs Supply}

Criminalisation of Khat Use: The government recently announced that it is to classify Khat as a Class $\mathrm{C}$ drug. The change in legislation will come into force in early 2014.

Possible withdrawal symptoms will need to be considered when Khat can no longer be commercially imported into the UK legally. Safer Bristol is currently working with its primary stakeholders, such as the Avon \& Somerset Police to discuss the impact of enforcement of the ban and treatment for users, together with education and awareness, treatment provisions, community concerns, and illegal supply and enforcement.

Impact on Communities: Along with fear of crime, drug misuse and drug dealing are amongst the greatest concerns to the quality of life in the city and can blight local communities ${ }^{23}$. The 2012 Quality of Life Survey showed $25 \%$ of

\footnotetext{
${ }^{20}$ Porter, K., 'Alcohol Strategic Needs Assessment': http://www.bristol.gov.uk/sites/default/files/documents/community and safety/safer bristol/Alcohol\%20Strategic\%20Needs\%20Assessment\%2 02012\%20final.pdf (accessed: $17^{\text {th }}$ April 2013)

${ }^{21}$ Safer Bristol Partnership, 'Commissioning a Recovery Orientated Substance Misuse Treatment System for Bristol - Commissioning Strategy 2012 - 2015:

http://www.bristol.gov.uk/sites/default/files/documents/community and safety/safer bristol/Commissioning\%20a\%20Recovery\%200rientated\% 20Substance\%20Misuse\%20Treatment\%20System\%20for\%20Bristol\%20Commissioning\%20Strategy\%202012\%20-\%202015.pdf (accessed: $17^{\text {th }}$ April 2013)

22 Trigger offences include: theft, robbery, burglary, aggravated burglary, taking motor vehicle or other conveyance without authority, aggravated vehicle-taking, obtaining property by deception, going equipped for stealing, restriction on production and supply of controlled drugs, possession of controlled drug and possession of controlled drug with intent to supply.
}

${ }^{23}$ Bristol City Council, 'Quality of Life in Bristol 2012' (March 2013). 
respondents thought there was a problem with drug use in their local area, which is a reduction from $36 \%$ in 2006 . This indicator showed a huge variation across the city with twice as many residents thinking this was a problem in deprived wards (for example, $66.1 \%$ of residents in Filwood concerned about crime in their area compared with residents in Clifton where only $2.4 \%$ said the same). Concern with drug use in the local area had also dropped for all the equalities groups, although it was significantly higher than average for people of Muslim faith (40\%), disabled people (37.1\%), BMEs (34\%) carers (30\%), and Lesbian, Gay, Bisexual and Transgender (LGBT) (30\%).

The proportion of respondents who say drug dealing is a problem in their area has not changed at $47 \%$ since 2012 . As with the indicator for perception of drug use, more residents perceived a problem in Filwood (80\%), for disabled people (58.4\%), carers (54\%), BMEs (53\%), LGBT (48\%) and people of Muslim and Christian faiths (69\% and $48 \%$ respectively).

\section{Restorative Approaches in Bristol}

Bristol aims to be a restorative city. Restorative Bristol defines the approach using a set of key principles, which are:

- Facilitating dialogue between all those affected by the wrongdoing or conflict.

- Encouraging those responsible for the harm done to become accountable for their actions and responsible for putting right the wrong.

- Ensuring that all those involved or affected are given the opportunity to share their story, their feelings and their needs.

- Involving everyone affected in finding mutually acceptable ways forward.

- Repairing the harm caused by any behaviour that has a negative impact on others.

- Repairing, or at times, building relationships between those affected.

The use of restorative approaches in Bristol can be seen via the Youth Offending Team (YOT) initiatives. ${ }^{24}$ The YOT has offered restorative justice solutions to 119 victims. At the same time, Victim Support and YOT have developed a new working arrangement whereby Victim Support volunteers are able to accompany YOT staff when they undertake their initial visits to victims. The purpose of this YOT visit is to explain the restorative justice options to victims and ensure that they are able to make an informed decision about whether to engage.

\section{Stop and Search Consultation 2013}

The Home Office launched a Stop and Search consultation, between July and September 2013.25 The consultation concerned those powers used in relation to street crime, burglary, anti-social behaviour, and public order offences such as riots and violent protests. Stop and search powers under counter-terrorism legislation have been the subject of recent changes and are not within the scope of this consultation.

Safer Bristol will wait for the outcome of the consultation and work together with its strategic partners to implement the key recommendations.

\section{Youth Offending}

Ashfield Youth Offenders Institution is due to close which has a number of impacts. If the numbers coming in to the formal youth justice system are reduced, fewer offenders will go further on through the system and reach the stage where custody is inevitable. With reduced caseloads because of reduced entrants in to the system, YOT staff will have more time to focus on the young people supervised on community penalties or leaving custody. The continuing confidence of local courts in the capacity of the YOT to supervise community penalties successfully means less resort to custody.

Future trends and activities that will impact YOT are:

- Change in the system of pre-court disposals in April 2013, which provides greater opportunity for YOT to undertake prevention work at an earlier stage, and the decision-making process in the cautioning system is now a joint process between the Police and the YOT.

- Devolved the financial responsibility for the costs of secure remands and remands in custody to YOT Boards and the Council in April 2013. This is seen as a huge financial risk, and the decision about where to place the young person, remains with the Youth Justice Board centrally. Use of remand reduced by $17 \%$ in

\footnotetext{
${ }^{24}$ YOT is a multi-agency team who deals with young offenders in setting up community services and reparation plans.

${ }^{25}$ Home Office, Stop and Search: https://www.gov.uk/government/consultations/stop-and-search (accessed: $20^{\text {th }}$ September 2013).
} 
2012/2013. The position is currently containable but custodial remands are the element of the youth justice system most subject to the impact of events.

- The new Police custody suites that will serve the North of the Avon and Somerset area from April 2014 may create some challenges. The travelling distance will increase for the young people, parents and carers. This may also lead to an increase in demand on the Appropriate Adult Services provided by the YOT in the North of the Avon and Somerset area.

- Import a programme for work with young women and girls developed by Leeds YOT which has received national recognition.

- Offer a programme of early intervention to all young people being cautioned where they have previously been subject to a Youth Restorative Disposal.

- Relocation of the team to CYPS in 2014, to improve access to the support services, reduce the likelihood of resort to custodial remands, and increase access to services that can reduce vulnerability.

- Develop and co-ordinate the delivery of a collaborative Appropriate Adult Scheme to the new custody suites, and improve the current arrangements in Bristol, Bath \& North East Somerset and South Gloucestershire. 


\section{Overview of Crime and Community Confidence}

Total crime numbers are at the lowest they have been in 12 years. This is despite the credit crunch, economic downturn and the introduction of austerity measures in 2008, recorded crime levels in the core cities of England and Wales have continued to fall. 26

In 2012/2013, there were 40,556 offences recorded in Bristol, a 14.6\% reduction from 2011/2012 numbers. Figure 1 below shows the downward trend over the last 12 years, and it is anticipated that such a trend will continue next year.

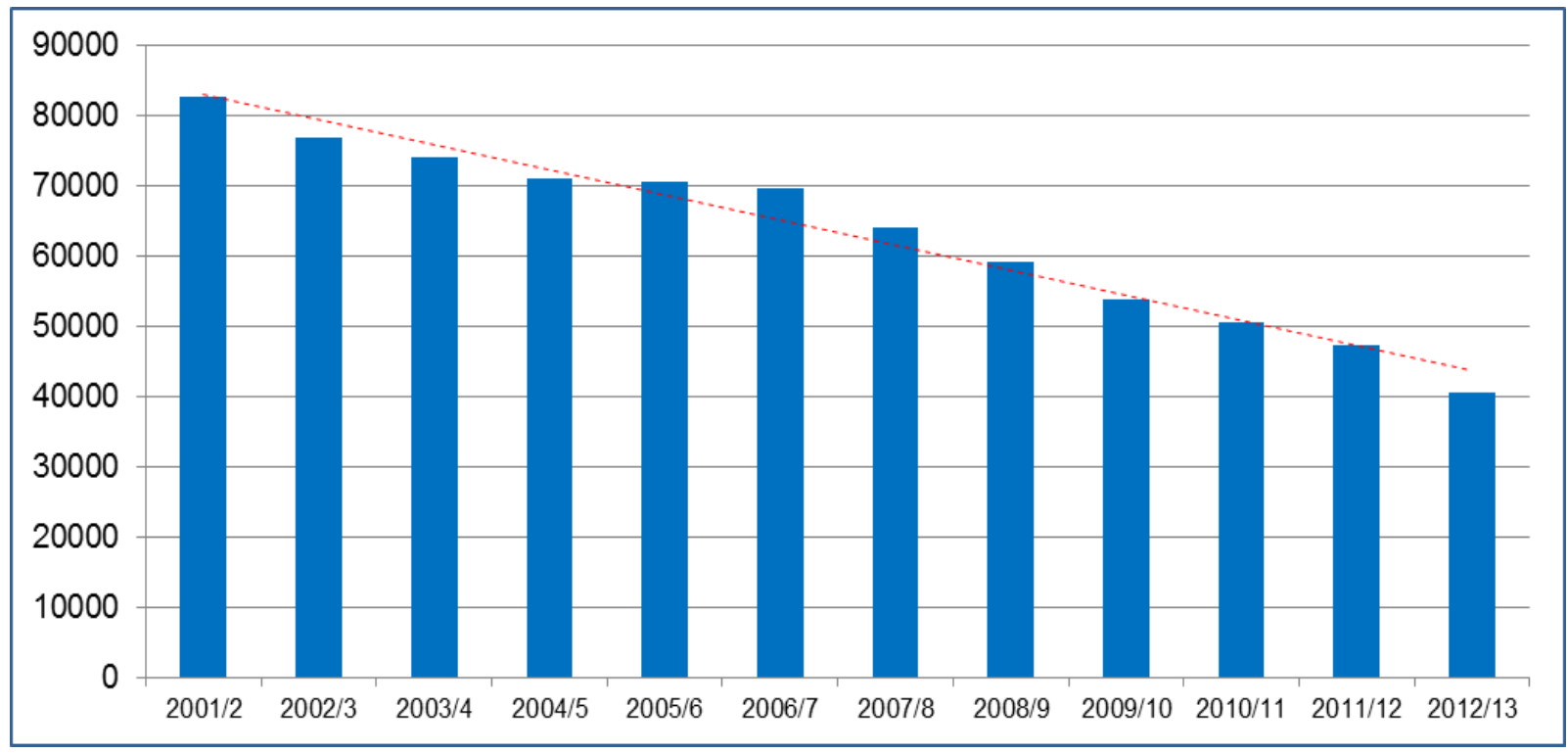

Figure 1: Recorded Crime in Bristol ${ }^{27}$

Since 2007, each of Core Cities has experienced a reduction in crime, of greater than $28 \%$. Table 1 below shows that it has mainly been reductions in theft from vehicles, criminal damage to vehicle and criminal damage to dwellings that have contributed to these falls.

\begin{tabular}{|c|c|c|c|c|c|c|c|c|}
\hline & Birmingham & Bristol & Leeds & Liverpool & Manchester & Newcastle & Nottingham & Sheffield \\
\hline $\begin{array}{c}\text { Change } \\
2007- \\
2012\end{array}$ & $32 \%$ & $36 \%$ & $28 \% V$ & $31 \%$ & $38 \%$ & $28 \% \nabla$ & $45 \%$ & $37 \%$ \\
\hline $\begin{array}{l}\text { The } \\
\text { largest } \\
\text { reduction } \\
\text { since } \\
2007\end{array}$ & $\begin{array}{l}\text { Assault with } \\
\text { injury (25\%) }\end{array}$ & $\begin{array}{l}\text { Theft } \\
\text { from } \\
\text { vehicle } \\
(22 \%)\end{array}$ & $\begin{array}{c}\text { Burglary } \\
\text { dwelling } \\
(19 \%)\end{array}$ & $\begin{array}{c}\text { Criminal } \\
\text { damage } \\
\text { to } \\
\text { vehicle } \\
(19 \%)\end{array}$ & $\begin{array}{l}\text { Theft from } \\
\text { vehicle } \\
(21 \%)\end{array}$ & $\begin{array}{l}\text { Criminal } \\
\text { damage to } \\
\text { vehicle } \\
(17 \%)\end{array}$ & $\begin{array}{l}\text { Theft from } \\
\text { vehicle }(17 \%)\end{array}$ & $\begin{array}{c}\text { Theft from } \\
\text { vehicle } \\
(16 \%)\end{array}$ \\
\hline $\begin{array}{l}\text { The } \\
\text { second } \\
\text { largest } \\
\text { reduction } \\
\text { since } \\
2007\end{array}$ & $\begin{array}{l}\text { Criminal } \\
\text { damage to } \\
\text { vehicle } \\
(14 \%)\end{array}$ & $\begin{array}{l}\text { Other } \\
\text { theft } \\
(13 \%)\end{array}$ & $\begin{array}{c}\text { Criminal } \\
\text { damage } \\
\text { to } \\
\text { vehicle } \\
(17 \%)\end{array}$ & $\begin{array}{c}\text { Criminal } \\
\text { damage } \\
\text { to } \\
\text { dwelling } \\
(15 \%)\end{array}$ & $\begin{array}{l}\text { Criminal } \\
\text { damage to } \\
\text { dwelling } \\
(14 \%)\end{array}$ & $\begin{array}{l}\text { Theft from } \\
\text { vehicle } \\
(15 \%)\end{array}$ & $\begin{array}{l}\text { Burglary } \\
\text { dwelling } \\
(13 \%)\end{array}$ & $\begin{array}{c}\text { Criminal } \\
\text { damage } \\
\text { to vehicle } \\
(16 \%)\end{array}$ \\
\hline $\begin{array}{l}\text { The third } \\
\text { largest } \\
\text { reduction } \\
\text { since } \\
2007\end{array}$ & $\begin{array}{l}\text { Theft from } \\
\text { vehicle } \\
(13 \%)\end{array}$ & $\begin{array}{c}\text { Criminal } \\
\text { damage } \\
\text { to vehicle } \\
(12 \%)\end{array}$ & $\begin{array}{c}\text { Criminal } \\
\text { damage } \\
\text { to } \\
\text { dwelling } \\
(14 \%)\end{array}$ & $\begin{array}{l}\text { Theft from } \\
\text { vehicle } \\
(14 \%)\end{array}$ & $\begin{array}{l}\text { Criminal } \\
\text { damage to } \\
\text { vehicle } \\
(12 \%)\end{array}$ & $\begin{array}{l}\text { Criminal } \\
\text { damage to } \\
\text { dwelling } \\
(15 \%)\end{array}$ & $\begin{array}{c}\text { Criminal } \\
\text { damage to } \\
\text { dwelling } \\
(12 \%)\end{array}$ & $\begin{array}{c}\text { Assault } \\
\text { with injury } \\
(14 \%)\end{array}$ \\
\hline
\end{tabular}

Table 1: Reduction in Crime since 2007

\footnotetext{
${ }^{26}$ University College London (UCL) Jill Dando Institute of Security and Crime Science (2013).

${ }^{27}$ Avon \& Somerset Neighbourhood Statistics, Recorded Crime Performance \& Crime for Bristol (2013)
} 
On the other hand, Table 2 below shows the top three highest volume crime type contributing to the crime fall, listed in relation to the rank each crime type contributed to its city's crime fall, and an 'other' column showing proportions where this crime type was not ranked in the top three for its city.

\begin{tabular}{|c|c|c|c|c|}
\hline & $\begin{array}{l}\text { The highest volume } \\
\text { crime type contributing } \\
\text { to the crime fall }\end{array}$ & $\begin{array}{l}\text { The second highest } \\
\text { volume crime type } \\
\text { contributing to the } \\
\text { crime fall }\end{array}$ & $\begin{array}{c}\text { The third highest } \\
\text { volume crime type } \\
\text { contributing to the } \\
\text { crime fall }\end{array}$ & Others \\
\hline $\begin{array}{l}\text { Theft from } \\
\text { vehicle }\end{array}$ & $\begin{array}{ll}\text { - } & \text { Bristol } \\
\text { - } & \text { Nottingham } \\
\text { - } & \text { Manchester } \\
\text { - } & \text { Sheffield }\end{array}$ & - Newcastle & $\begin{array}{ll}\text { - } & \text { Birmingham } \\
\text { - } & \text { Liverpool }\end{array}$ & - Leeds \\
\hline $\begin{array}{l}\text { Criminal } \\
\text { damage to } \\
\text { vehicle }\end{array}$ & $\begin{array}{ll}\text { - } & \text { Liverpool } \\
\text { - } & \text { Newcastle }\end{array}$ & $\begin{array}{ll}\text { - } & \text { Birmingham } \\
\text { - } & \text { Sheffield } \\
\text { - } & \text { Leeds }\end{array}$ & $\begin{array}{ll}\text { - } & \text { Bristol } \\
\text { - } & \text { Manchester }\end{array}$ & - Nottingham \\
\hline $\begin{array}{l}\text { Criminal } \\
\text { damage to } \\
\text { dwelling }\end{array}$ & & $\begin{array}{l}\text { - } \quad \text { Liverpool } \\
\text { - }\end{array}$ & $\begin{array}{ll}\text { - } & \text { Leeds } \\
\text { - } & \text { Newcastle } \\
\text { - } & \text { Nottingham }\end{array}$ & $\begin{array}{ll}\text { - } & \text { Birmingham } \\
\text { - } & \text { Sheffield } \\
\text { - } & \text { Bristol }\end{array}$ \\
\hline
\end{tabular}

Table 2: Top Three Highest Volume Crime Type Contributors to the Crime Fall

Figure 2 below shows the 12 year crime trend in Bristol, where on average, 111 crimes took place in the local area on a daily basis. Of these crimes, on average,

- 19 serious acquisitive crimes happened in Bristol daily

- 22 violence against person cases happened on a daily basis

- 19 domestic violence and abuse cases took place on a daily basis

- Two sexual offences were recorded daily.

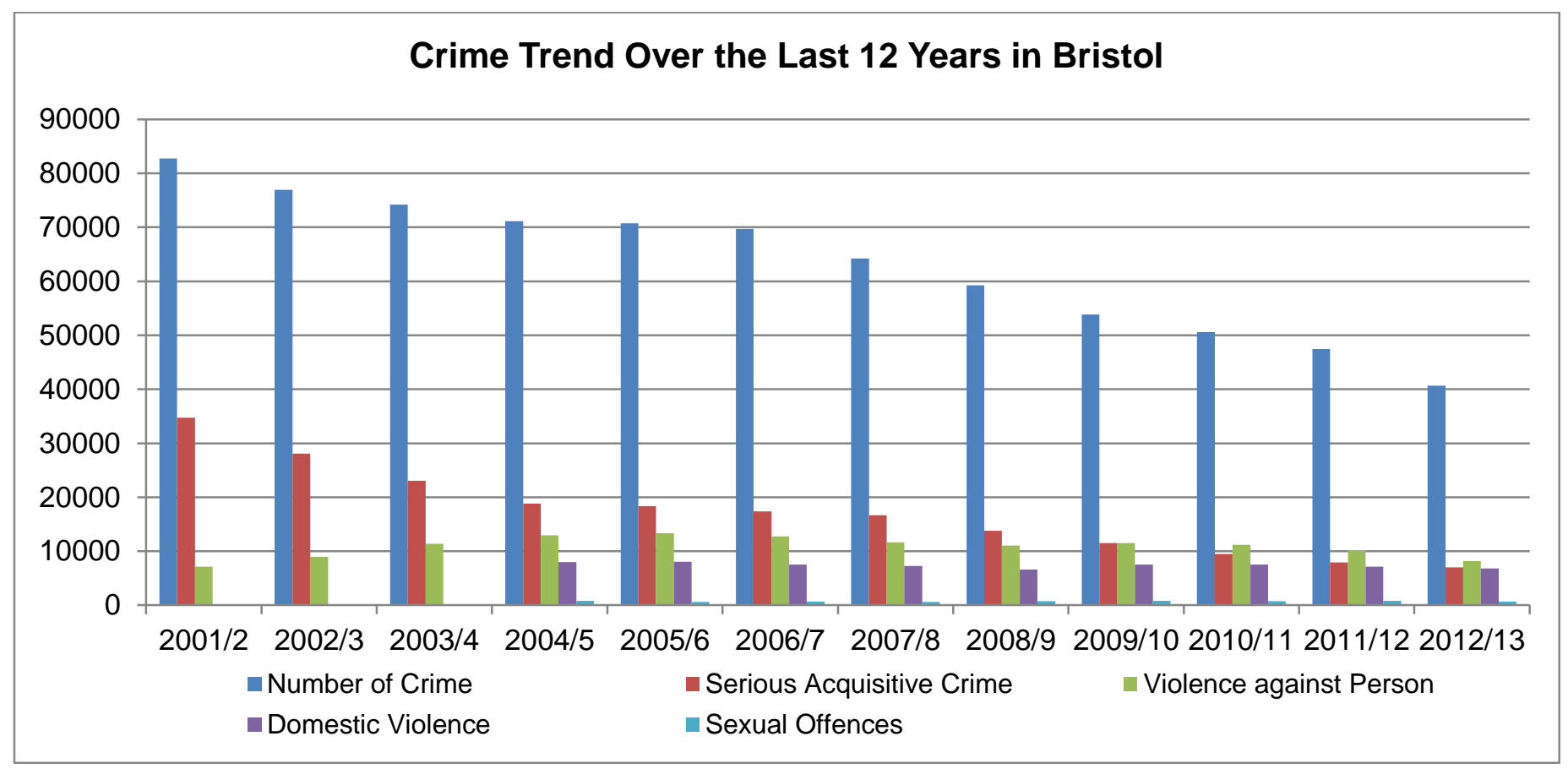

Figure 2: 12 Years Crime Trend in Bristo ${ }^{28}$

${ }^{28}$ Note that there is no data for domestic violence and sexual offences between 2001/2002 and 2003/2004. 
In Bristol, the total crime detection rate in 2012/2013 was 33\%. This is coupled with the fact that $71 \%$ of Avon and Somerset residents have confidence in their local Police force. ${ }^{29}$ Public perceptions of crime have also improved. This can be seen in the Bristol City Council's Quality of Life Survey 2012. This is an annual survey conducted by Bristol City Council, which provides an insight into life in Bristol. The results are used by the Council and its partners, including Avon \& Somerset Police to help plan local services, track change, and improve the quality of life for residents of Bristol.

Key findings of the survey are:

- Victims of crime in the last $\mathbf{1 2}$ months - The percentage of respondents who have been victims of crime in the past 12 months corresponds with Police crime data and has continually diminished since the survey began in 2005. It is now 13.6\%, 9.9\% lower than the 2006 percentage.

- Whether crime has worsened in the past three years - Only $16.7 \%$ of respondents now feel that crime has worsened in the past three years. This is a reduction of $1.5 \%$ compared to the 2011 survey, and a significant improvement compared with 2006 when $36.4 \%$ of respondents felt this was an issue.

- Crime in priority neighbourhood areas - Public perceptions of crime have worsened in priority neighbourhood areas ${ }^{30}$ in 2012 compared to $2011(+2.5 \%)$, in which three out of ten people feel that their day-to-day life is affected by fear of crime. Nevertheless, this is still considered as a significant improvement compared with 2006 when $40.4 \%$ of respondents felt fear of crime was an issue.

- Day-to-day life is affected by fear of crime - The percentage of respondents whose day-to-day life is affected by fear of crime is now $21.2 \%$ (17.8\% lower than when the survey first began in 2005).

- Personal safety is a problem in their neighbourhood - Just above a quarter (26\%) of the respondents believe that their personal safety is a problem in their neighbourhood, compared to $40 \%$ who mentioned the same issue in 2006 . The same percentage of respondents mentioned the same problem in the last year's survey.

- Vandalism is a problem - $48 \%$ of the respondents feel that vandalism is a problem in their local area. This represents a six percent reduction compared to last year's responses, and an $18 \%$ reduction compared to responses in 2005.

- Police and local public services are successfully dealing with crime and anti-social behaviour - $38 \%$ of the respondents believe that this is the case, although this is slightly reduced from $40 \%$ last year.

\section{Location}

Safer Bristol produces a table of all crime types by Neighbourhood Policing Area for 2012/13 (NDT Scorecard) ${ }^{31}$. The NDT scorecard will also be broken down by ward level to help inform Neighbourhood Working. This information is available on request and will be updated on a quarterly basis.

\section{Recommendation}

- $\quad$ The information contained in the Strategic Assessment will be broken down via Neighbourhood Partnership areas to support local delivery of neighbourhood working.

- Explore with core cities further analysis and problem solving techniques that look into trends across priority crime areas.

- Continue to share good news on community safety issues in Bristol to improve people's confidence in the local area

- Inform Joint Strategic Needs Assessment (JSNA) and the PCC Needs Assessment to set priorities for the partnership working

\footnotetext{
${ }^{29}$ Crime Survey for England and Wales (December 2012).

${ }^{30}$ Priority neighbourhood areas are defined as the areas that the Council considered as deprived. These areas are: Ashley, Filwood, Hartcliffe, Lawrence Hill, Southmead and Whitchurch Park wards.

${ }^{31}$ NDT is a group of local officers from the main public and voluntary sector who meet on a monthly basis to discuss issues affecting the local area.
} 


\section{Acquisitive Crime}

\section{Overview}

'Acquisitive Crime' is defined as offences where the offender derives material gain from the crime. 'Serious acquisitive crime' is a subset of acquisitive crime, which consists of offences such as domestic burglary, car crime (theft of a vehicle and theft from a vehicle) and robbery.

During 2012/2013, 41\% of all crime in Avon and Somerset area happened in Bristol, and almost half of which (47\%) related to acquisitive crime. On average, six domestic burglaries, two robberies, three thefts of motor vehicles and eight thefts from motor vehicles took place in Bristol on a daily basis.

The $80 / 20$ principle suggests that approximately $80 \%$ of offences will be committed by the most active $20 \%$ of criminals. The $80 / 20$ principle mainly applies to crimes of the acquisitive types. The Ministry of Justice research shows that $57.9 \%$ of adult offenders and $36.2 \%$ of juvenile offenders convicted of a theft offence go on to re-commit a similar offence in the following year.

Repeat offenders like these are most often problematic drug users who are committing crimes to sustain their drug use. They often have many other problems including homelessness, learning disabilities, alcohol abuse, and mental health problems. In order to reduce crime in the long term it is widely recognised that offenders need support to address the issues they face in order to reduce offending.

\section{Performance}

In 2012/2013, 7003 serious acquisitive crimes were recorded by the Police in Bristol. This is a substantial decrease compared to the last financial year when there were just under 8,000 serious acquisitive crimes recorded in Bristol. This trend continues with an 18\% reduction year-to-date, with 338 fewer victims of this type of crime.

Figure 3 below shows the downward trend for acquisitive crime on a yearly basis:

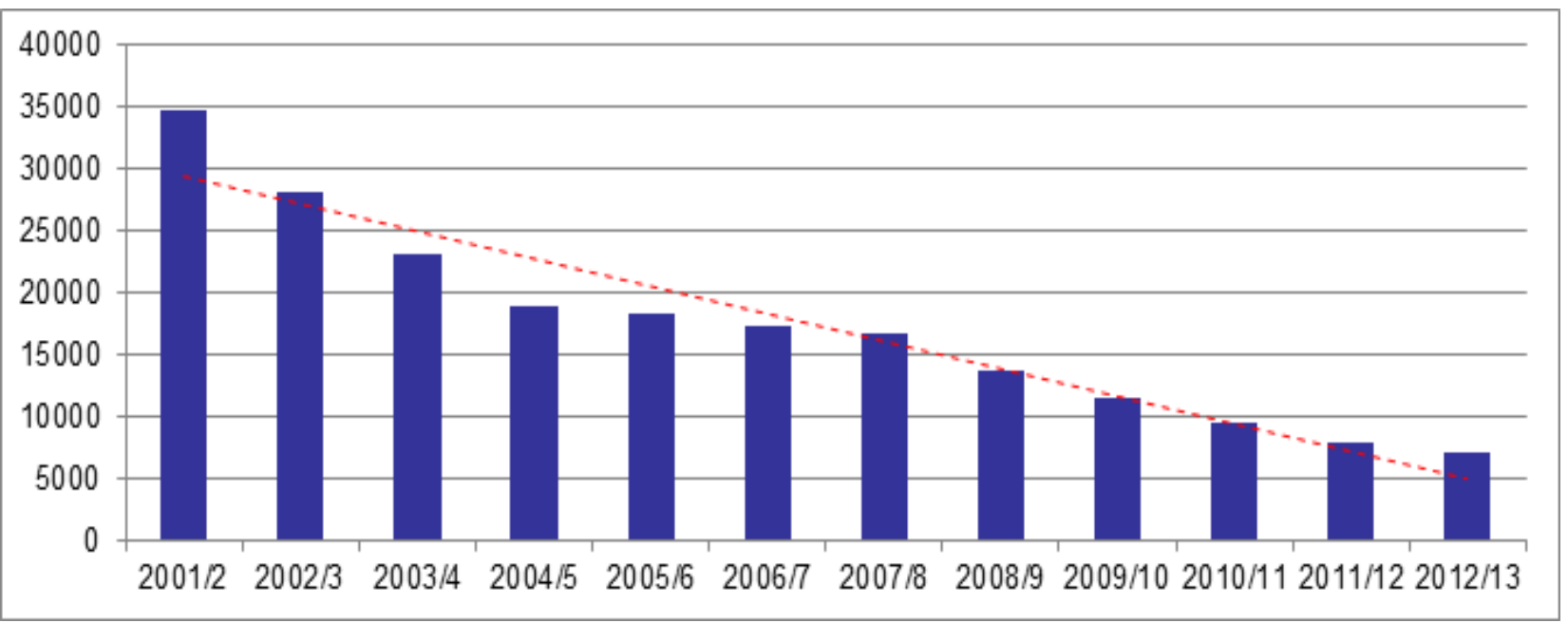

Figure 3: Serious Acquisitive Crime Over the Last 12 Years in Bristol

\footnotetext{
${ }^{32}$ Essentially Burglary, Robbery, Theft of Motor Vehicle and Theft from Motor Vehicle.
} 




Figure 4: Acquisitive Crime in Bristol $2006-2013$

Looking at the trend of acquisitive crime in Bristol since 2006, there was a decrease in all offences (with the exception of shoplifting), particularly vehicle crime and domestic burglary.

\begin{tabular}{lcccc}
\hline $\begin{array}{l}\text { Offence } \\
\text { 2012-13 }\end{array}$ & $\begin{array}{c}\text { Bristol Rate /1000 } \\
\text { Population }\end{array}$ & $\begin{array}{c}\text { Core City Average } \\
\text { Rate /1000 } \\
\text { Population }\end{array}$ & $\begin{array}{c}\text { Core City } \\
\text { Comparison } \\
\text { Rank (Out of 8) }\end{array}$ & $\begin{array}{c}\text { Bristol Average } \\
\text { Crimes Per Day }\end{array}$ \\
\hline Serious acquisitive crime & 16.2 & 17.2 & 2 & 19 \\
Domestic burglary & 5.7 & 6.6 & 2 & 7 \\
Robbery & 1.5 & 1.9 & 7 & 2 \\
Shoplifting & 10.5 & 8.5 & 8 & 12 \\
Vehicle crime & 9.8 & 9.2 & 8 & 12 \\
Other theft & 10.6 & 9.6 & 3 & 13 \\
Theft and handling & 28.6 & 25.7 & 3 & 34 \\
\hline
\end{tabular}

Table 3: Acquisitive Crime Per Thousand Population - Core Cities Comparison

\begin{tabular}{|l|c|c|c|c|c|c|c|}
\multicolumn{1}{c|}{} & \multicolumn{7}{c|}{ Bristol Core City Ranking } \\
\cline { 2 - 9 } \multicolumn{1}{c|}{} & $\mathbf{2 0 0 6 / 2 0 0 7}$ & $\mathbf{2 0 0 7 / 2 0 0 8}$ & $\mathbf{2 0 0 8 / 2 0 0 9}$ & $\mathbf{2 0 0 9 / 2 0 1 0}$ & $\mathbf{2 0 1 0 / 2 0 1 1}$ & $\mathbf{2 0 1 1 / 2 0 1 2}$ & $\mathbf{2 0 1 2 / 2 0 1 3}$ \\
\hline Domestic Burglary & 4 & 5 & 5 & 7 & 5 & 4 & 2 \\
\hline Robbery & 5 & 5 & 5 & 5 & 5 & 5 & 7 \\
\hline Shoplifting & 5 & 6 & 8 & 8 & 7 & 6 & 8 \\
\hline Vehicle crime & 6 & 6 & 6 & 7 & 5 & 6 & 8 \\
\hline Other theft & 6 & 6 & 6 & 6 & 5 & 6 & 3 \\
\hline Theft and handling & 4 & 5 & 4 & 4 & 4 & 3 & 3 \\
\hline
\end{tabular}

Table 4: Distance Travelled for Bristol in the Last Seven Years Compared to Other Eight Core Cities Based on Total Crime Rate $^{34}$

When comparing Bristol's core city ranking in $2012 / 13$ to $2011 / 12$ based on the total crime rate, domestic burglary, other theft, theft and handling, and vehicle crime ${ }^{35}$ are moving in the right direction. However, robbery, shoplifting and vehicle crime have worsened over the years.

\footnotetext{
${ }^{33}$ One is the best and eight is the worst.

${ }^{34}$ Note that serious acquisitive crime data is not available for comparison.

${ }^{35}$ Note that although there has been a reduction in vehicle crime, Bristol is still behind other Core Cities in England.
} 
Victim

The victims' profile can be divided into crime type as follows:

- Personal Robbery

There were 607 robbery victims that were identified through the Police system:

- Gender: $75 \%$ of the victims were male (455) and the remaining was female (150).

- Age: The victims tend to be younger, aged $16-24$ (252, 42\%) and $25-34$ (139, 23\%).

- Ethnicity: The largest group of ethnicity for domestic robbery victims is White British (418,69\%).

- Locations: The top three wards with the largest number of offenders are Cabot (108, 18\%), Ashley (91, 15\%) and Lawrence Hill $(88,14 \%)$.

- Domestic Burglary

There were 4,474 domestic burglary victims that were identified through the Police system:

- Gender: $46 \%$ of the victims were male $(2,074)$ and the remaining $36 \%$ were female $(1,615)$. $18 \%$ of the victims' gender was not collected.

- Age: The largest victim age group that were subject of domestic burglary is between 25 and 34 (916, 20\%). It is noted that another $20 \%$ of the data is incomplete.

- Ethnicity: Six out of ten victims $(2,678)$ had White British background. Slightly more than a quarter of the victim data, the ethnicity $(1,219,27 \%)$ was not recorded.

- Locations: Three wards where the highest number of victims live are Cabot (375, 8\%), Lawrence Hill (230, $5 \%)$ and Eastville (179, 4\%).

\section{- Safer Homes Scheme}

To reduce repeat victimisation, the Safer Homes Scheme visited $93 \%(1,509)$ of burglary victims across Bristol to take practical steps to reduce repeat burglary rates. In some areas of Bristol there was previously a one-in-three chance of being victimised again. The biggest portion of clients came from the 50 and above age group (376, 25\%) and White British (877, 58\%). Of these victims, the scheme benefited 414 domestic violence and abuse victims, 387 burglary victims, and 68 anti-social behaviour victims.

\section{- Asian Gold Burglaries}

Over the last year there has been considerable anxiety in Bristol's Asian communities (primarily Pakistani, Indian and Bangladeshi) because of a spate of targeted burglaries. This is because it is known that traditionally Asian women will acquire gold especially at the time of getting married. Although burglaries have not been disproportionately high relative to the population, there is clearly targeting of these households that has resulted in increased fear of burglary.

In 2012/2013, there were 74 burglary offences of gold against Asian victims. The number of offences is not disproportionate to the population. However, attention was given to this emerging issue to respond to the specific needs of the community. This number does include all dwelling burglaries where the victim is Asian, or if the intention of the suspects cannot be established. From April 2013 to date, there were 20 offences reported to the Police as specifically being Asian gold burglaries, which shows a positive trend compared to last year.

Operation Blueprint has been set up by Avon and Somerset Police to respond to a spate of gold burglaries particularly affecting Asian communities over the last year. A peak in November 2012 coincides with the arrest of three travelling offenders from London, who were charged with five Operation Blueprint offences in that month, and in the immediate weeks after the arrests, the numbers of offences dropped considerably.

The Police have been in active dialogue with people from Asian communities to report on what is being done to detect and address these crimes and to advise people on securing their homes and reporting any type of suspicious behaviour near their properties. The Police, together with support agencies and Safer Bristol organised a crime reduction event for Asian communities on $14^{\text {th }}$ April 2013 to offer advice and guidance. There is on-going work to support the community and prevent burglaries through target hardening and the apprehension of offenders. 


\section{- Mobile Phone Theft}

Recently, the Jill Dando Institute of Crime Science, University College London, together with other core cities, worked to produce a research report on mobile phone theft. Police data on theft from person and theft other covering the financial years of 2011/2012 and 2012/2013 has been reviewed to further our understanding of mobile phone theft.

In Bristol, data on the victims' age shows the majority are younger adults, which could include students. In 2012-13, $30 \%$ of the victims of theft were aged 16 to 24 and a further $22 \%$ were aged 25 to 34 . Targeted Police activity has taken place at live music venues in Bristol, as intelligence suggested that organised crime groups target these venues across the UK to steal large volumes of phones from people while they are dancing. The Police have run an awareness campaign which involved putting stickers on phones in public places that could have been stolen. Bristol has also adopted a Market Reduction Approach which aims to make the risk of selling stolen goods as risky as the act of stealing.

Looking at the core cities data, mobile phone theft has been the driving force behind the increase in the theft from the person in all core cities, except Birmingham. ${ }^{36}$ Whilst mobile phone ownership has remained relatively unchanged over the last five years, ownership of smartphones has rapidly increased. In 2013 , approximately $48 \%$ of people in core cities in the UK own a smartphone. The following hypotheses were suggested as the key reasons for explaining the mobile phone theft problem:

- A small number of licensed premises are responsible for a large proportion of the volume and increase in mobile phone theft, with these offences mainly occurring on Friday and Saturday evenings.

- A disproportionate number of mobile phone victims in the core cities are students.

- Victims do not take appropriate steps to prevent their phone from being stolen because the financial value of the phone (if stolen) is of little significance as the phone is easy to replace at no cost to the victim.

- The majority of mobile phones that are stolen locally are being sold locally in second hand shops, rather than being shipped further afield or sold to recycling outlets.

A number of recommendations have been made to tackle the mobile phone theft issues in Bristol, which will be considered by the partnership.

\section{Offender}

The following sections give us the details of the demographic patterns of acquisitive crime offenders:

\section{- Personal Robbery}

There were 124 personal robbery offenders that were identified through the Police system:

- Gender: Almost three quarters of the offenders were male (92).

- Age: The largest offender group that committed domestic burglary is between 16 and 24 years.

- Ethnicity: Seven out of ten offenders were from a White British background

- Locations: The top three wards where these offenders came from are Cabot (22, 18\%), Lawrence Hill (16, $13 \%)$ and Ashley (15, 12\%).

\section{- Domestic Burglary}

In total, there were 421 domestic burglary offenders identified on the Police system. The demographic profile of these offenders is:

- Gender $-42 \%$ (175) of the offenders were male, whilst another $30 \%$ were female. It is noted that $28 \%(118)$ of the offenders had not had their genders recorded.

- Age - The largest age group for this offence came from 25 to 34 years (81, 19\%). However, it is also recognised that the age of 128 offenders $(30 \%)$ was not recorded on the system.

- Ethnicity - Half of the offenders (212) were from a White British background. At the same time, it is recognised that $38 \%$ of the offenders' ethnicities (159) were not recorded.

- Location - 15\% (64) of the offenders came from Cabot ward, followed by Lawrence Hill $(25,6 \%)$ and both Brislington East and Eastville (17, 4\%) respectively.

${ }^{36}$ Chainey. S., 'Phase 2: Understanding Mobile Phone Theft in the Core Cities (2013). 
In total, there were 3,850 offenders of theft and handling identified on the Police system. The demographic profile of these offenders is:

- Gender - $10 \%$ (383) of the offenders were male, whilst another $7 \%(276)$ were female. It is noted that $83 \%$ $(3,191)$ of the offenders had not had their genders recorded.

- Age - The largest age group for this offence came from the group $25-34$ (172, 4\%). However, it is also recognised a large portion of the age data on the offenders were not collected (84\%).

- Ethnicity - 11\% (426) of the offenders were from a White British background. At the same time, it is recognised that $86 \%$ of the offenders' ethnicities $(3,301)$ were not recorded.

- Location - 34\% $(1,317)$ of the offenders came from Cabot ward, followed by Southville $(322,8 \%)$ and both Hartcliffe $(274,7 \%)$ respectively.

\section{- Integrated Offender Management (IMPACT)}

Avon and Somerset's most prolific offenders are predominantly those committing high volume acquisitive crimes. These offenders are managed through IMPACT, using the Integrated Offender Management (IOM) approach. IMPACT is a multi-agency team, including the Police, Probation and Safer Bristol. One of the most effective ways to cut crime is to focus the effort on people who are committing most of the crimes in Bristol. The offenders are selected based on offending history, lifestyle, and substance misuse. If the offenders do not co-operate with their orders, licences and support, the IMPACT team can implement enforcement action. IMPACT has received a strong investment from the key partners of the Police, Probation Trust, Safer Bristol, Prison Service, Criminal Justice Intervention Team (CJIT), and the voluntary and community sector.

As of September 2013, there are 644 IMPACT criminals in Bristol. The majority of the offenders were male $(90 \%$, $582)$ and White British $(80 \%, 516)$. The actual re-offending rate for this cohort of people was $10.8 \%$. In quarter 3 $2012 / 2013$, IMPACT offenders were also prosecuted for serious acquisitive crimes on average $29 \%$ faster than mainstream offenders prosecuted for the same crime type, well above the $15 \%$ target.

The current IMPACT cohort is categorised by the needs of the offenders. 172 offenders were classified as red (27\%), demonstrating high needs of the offenders. The average age of these offenders is 33 years old, and 42 offenders received intervention from the CJIT as part of their drug recovery.

In Bristol, the IMPACT team is co-located, comprising Police, Probation and CJIT workers, and this has been recognised nationally as a good practice. IMPACT remains a significant contributory factor in achieving reductions in serious acquisitive crime in Avon and Somerset.

Avon and Somerset Police currently runs a project on the use of restorative justice as part of IMPACT. This has been in place for more than two years, and all IMPACT offenders who have been sentenced are referred to the project on a weekly basis, for consideration on the use of restorative justice. Since April 2013, there have been 57 IMPACT referrals to the project, where 10 referrals progressed to the 'victim-contact' stage. Of these 10 referrals, three resulted in face-to-face meetings between the offenders and the victims. The referral stage is used to assess the suitability of the cases and whether they are appropriate for restorative justice intervention.

\section{Location}

\section{- Stolen Property Initiative}

A new initiative has been launched in Bristol to comprehensively understand the disposal routes of stolen property taken in priority crime offences. The focus is on the stolen goods market, particularly second hand outlets, where it is believed stolen property may be sold. The plan for the second hand outlets is to create a structured system in which officers will carry out regular coordinated visits to offer assistance and advice and check that they are complying with current 'due diligence' legislation. Training packages will also be created for both officers and the outlets that agree to join up with the scheme.

An intelligence gap in this part of the stolen goods market has also been identified. By setting up official information sharing channels among the outlets, intelligence will be improved. The information received will open up a new avenue for intelligence around second hand goods locations and offenders using them.

As well as focusing on second hand outlets, it was highlighted that there is a need for getting more people to register and mark their valuable property such as laptops, phones, bikes, and jewellery. 
This aspect of the project will give the police a greater chance of identifying property as lost or stolen resulting in the reduction of crimes, a disruption of potential outlets used by offenders to dispose of stolen items, and an increase in the return of property to its lawful owner.

One obstacle faced is the lack of legislation around the second hand goods market. Therefore, visits will rely on the co-operation and goodwill of the outlets involved. The Police have been in dialogues with Bristol City Council about the possibility of creating local legislation as councils in other areas have already done.

\section{- Mobile Phone Theft}

To combat young people's mobile theft, the mobile phone of all offenders coming into custody is checked to ascertain if it is stolen property. The modus operandi of mobile phone thefts has been identified as the following:

- Offenders tend to sell stolen goods on to known handlers, friends and relatives rather than strangers and experienced thieves tend to be proactive in establishing new routes to dispose of stolen property. ${ }^{37}$

- Thieves rarely store goods for more than an hour after the theft; they seek cash returns as soon as possible. ${ }^{38}$

- The links to drug use are well documented as acquisitive crime is commonly committed to fund substance misuse..$^{39}$

\section{Recommendations}

- Further exploration of the acquisitive crime areas (robbery, shoplifting and vehicle crime) that shows Bristol is under-performing in comparison to core cities, is needed to improve performance in these areas. Depending on existing structures it is suggested that task and finish groups are established to adopt a problem solving approach.

- Explore the possibility of local legislation around the second hand goods market, to ensure that the second hand shops conduct the necessary due diligence process before accepting goods from the members of the public.

- Ensure that the new Arrest Referral and Intervention Scheme within the new Detention Centres links effectively with IMPACT and CJIT.

- Ensure restorative justice approaches are recognised as a core intervention within offender management to help reduce re-offending

- Partnership to consider recommendations from the Jill Dando Institute on mobile phone theft.

- Continue to support the use of restorative approaches within IMPACT, aiming to increase the number of conferences and successful outcomes.

- Continue to support the multi-agency partnership delivery of offender management through the IMPACT and IRiS programmes

- Ensure that adequate training is available for IMPACT Probation staff to support the use of restorative justice when managing statutory offenders on the IMPACT caseload.

- Continued commitment for the use and expansion of the 'Buddi' voluntary tagging scheme for offenders

- Consider layering the data across projects such as Troubled Families, IRiS and IMPACT, to see whether there are cohort of offenders that can be jointly targeted.

- Improve data recording on victims and offenders, which will be addressed through the new crime recording solution of the Police.

\footnotetext{
${ }^{37}$ Sutton, M., 'How Prolific Thieves Sell Stolen Goods: Describing, Understanding and Tackling the Local Markets in Mansfield and Nottingham', Internet Journal of Criminology (2008).

${ }^{38}$ Centre for Problem Orientated Policing, 'Stolen Goods Markets' (March 2012).

${ }^{39}$ Home Office, 'Tackling Theft with the Market Reduction Approach' (2002).
} 


\section{Violent Crime}

\section{Overview}

Violent crime consists of the following offence types: wounding, assault with minor injury, assault without injury, robbery, domestic violence and abuse, stranger violence and acquaintance violence. Just under $40 \%$ of Avon and Somerset Police recorded violent crime occurs in Bristol (8,188 crimes in Bristol and 21,123 crimes across the Force in total). In Bristol, violent crime is addressed by the Police through Operation Brio (the City Centre night time economy response), and by Safer Bristol through the Violent Crime and Substance Misuse Strategy Group.

Bristol City Centre is a regional hub for night-time entertainment, attracting a transient population of students and visitors. It is estimated that there are over 220 venues within the city centre which operate after $5 \mathrm{pm}$. This statistic is a driver in the establishment of targeted tactical operations and services to reduce violence and anti-social behaviour. Violent crime reduction initiatives are co-ordinated through by the Neighbourhood Policing Teams. Partnership activity and responses are delivered by a number of multi-agency delivery groups.

\section{Performance}

In 2012/2013, the rate of violence against the person declined by $19 \%$ (8,188 as opposed to 10149 in $2011 / 2012)$. Figure 5 below shows the trend of violent crime for the last 12 years:

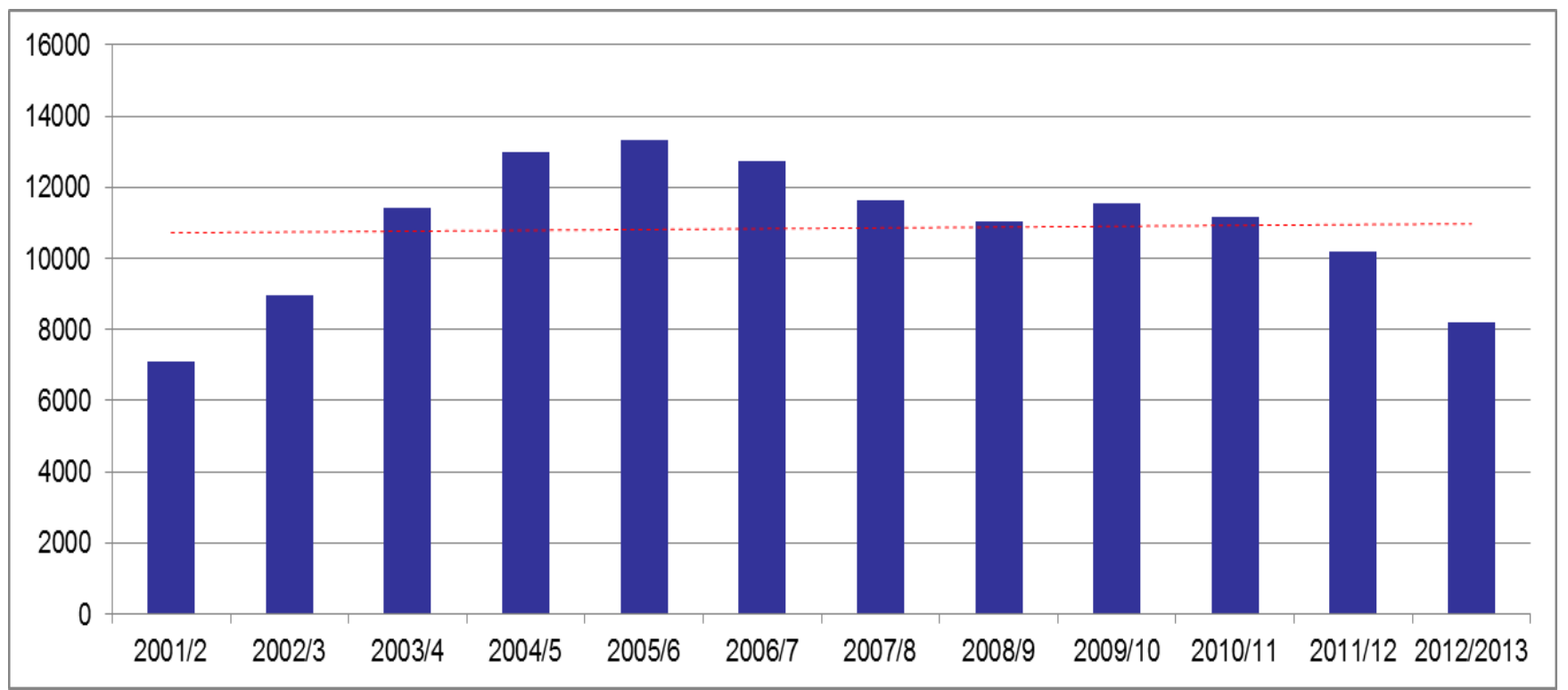

Figure 5: Violent Crime Over the Last 12 Years in Bristol

It is noted that above a quarter of violence against the person offences $(27.7 \%, 2,270)$ were related to domestic violence and abuse. Domestic Violence and abuse is dealt with under the appropriate section of this document.

Based on crime per thousand population, Bristol ranked sixth out of eight core cities for violent crime in 2012/2013:

\begin{tabular}{lc}
\hline Core Cities & Rate /1000 Population \\
\hline Sheffield & 10.23 \\
\hline Newcastle & 13.81 \\
Leeds & 14.41 \\
\hline Liverpool & 16.59 \\
Birmingham & 18.59 \\
Bristol & 22.58 \\
Manchester & 22.77 \\
\hline Nottingham & 26.07 \\
\hline
\end{tabular}

Table 5: Core City Comparison of Violent Crime Per Thousand Population 
It is noted that greater than $25 \%$ of violence against the person offences $(27.7 \%, 2,270)$ were related to domestic violence and abuse. Domestic Violence and Abuse and Robbery are dealt with under the appropriate section of this document.

The Quality of Life Survey 2012 contains a number of questions which monitor how citizens feel about crime in their communities. From the 2012 survey;

- 'Drunk and rowdy people in public places is a problem' - Half of the respondents (50\%) think that drunk and rowdy people in public places is a problem in their local area. The rate is the same as last year's survey, and a $3.7 \%$ reduction compared to responses in 2009.

- 'Feel safe when outside their neighbourhood during the day and after dark' - $90.5 \%$ respondents believe that they feel safe during the day when they are outside their neighbourhood areas. However, $59.4 \%$ respondents feel that they are safe outside after dark, an improvement compared to $40.7 \%$ who mentioned the same when the question was first asked in 2005.

Victim

There were 8,041 victims of violence against the person that could be identified from the Police system. One in ten of these victims was deemed to be a repeat victim of the same type of offence.

Table 6 below shows that the majority of the victims (67\%) were aged between 16 and 44 years. There is no variation that can be seen through the gender of the victims.

\begin{tabular}{lc}
\hline Age Group & Number of Victims \\
\hline 15 and under & 504 \\
$16-24$ & 1,989 \\
$25-34$ & 1,972 \\
$35-44$ & 1,389 \\
$45-54$ & 832 \\
$55-64$ & 271 \\
$65-74$ & 91 \\
75 and above & 45 \\
Not recorded & 948 \\
\hline
\end{tabular}

\begin{tabular}{lc}
\hline Gender & Number of Victims \\
\hline Male & 3,707 \\
Female & 3,707 \\
Not recorded & 627 \\
\hline
\end{tabular}

Table 6: Age Group of VAP Victims

Table 7: Gender of VAP Victims

'Peak Time Analysis' shows that just above a quarter of the incidents took place between 23:00pm and 02:00am. Most of the incidents reported in Bristol happened in Cabot $(1,636,20 \%)$ and Lawrence Hill $(884,11 \%)$ wards. Analysing the age groups, peak time and the locality of the offences, it can be inferred that the night time economy of the city is one of the factors that might have contributed towards the violence against the person.

Bristol Royal Infirmary collects assault data, which is used to inform prevention and tactical responses. In 2012/2013, there were 998 incidents recorded. This data collection is important to try to build a picture of where victims are being assaulted, as some people who go to hospital will not report the assault to the Police. These unrecorded violent crime incidents are a valuable source of information on where and when people have been injured, where some victims tend to go to Accident and Emergency (A\&E) and do not report the matter to the Police. At the same time, the database also recorded injuries suffered by the perpetrators. In this context, there will be intelligence that has been captured by the database, which is not necessarily collected by the Police.

South West Ambulance offers a night-time weekend triage service on the city centre. They treat people who have minor injuries and ailments before sending them home. This is a means of dispersing vulnerable people from the area and allowing them to travel home or to continue their evening.

\section{Offender}

There were 3,581 offenders had been identified through the Police system. $9 \%$ of the offenders (310) had committed violent offences more than once. 
A large proportion of the offenders came from the age groups of $16-24$ and $25-34$ years $(1,495,42 \%)$. There is no significant variation between male and female offenders $(1,521,42 \%$ and $1,453,41 \%$ respectively, with the remaining data not recorded).

In terms of the ethnicity of the offenders, 1,945 (54\%) were White British, although it is noted that the ethnicities of 1,032 offenders $(29 \%)$ were not recorded. A large number of offenders came from Cabot and Lawrence Hill wards $(1,209,34 \%)$, which is also in line with the wards of which the victims came from.

Looking into the sanctions imposed against these offenders, the majority of the offenders were charged with the offence $(2,252,63 \%)$. This is followed by cautioned $(540,15 \%)$ and restorative justice $(342,10 \%)$. The specific sanctions that are currently being used among these offenders are:

- Use of recorded Acceptable Behaviour Contract (ABC) for offenders. Current Police records show that 94 $A B C s$ have been recorded this year.

- Section 27 Dispersal Notices are being used to remove potential violent offenders from an area. These notices are recorded to deter offenders or in evidence against them if they choose to re-offend. 263 Notices have been issued since January this year.

- Standard bail conditions are being used to help keep repeat offenders from a particular area.

- Drinking Banning Orders (DBOs) are being applied for, through the courts to ban a repeat offender from a particular area at certain times. Four DBOs have been applied by the Police this year.

\section{Location}

Figure 6 below shows the year on year comparison of levels of recorded violence against a person in Bristol, by NDT areas:

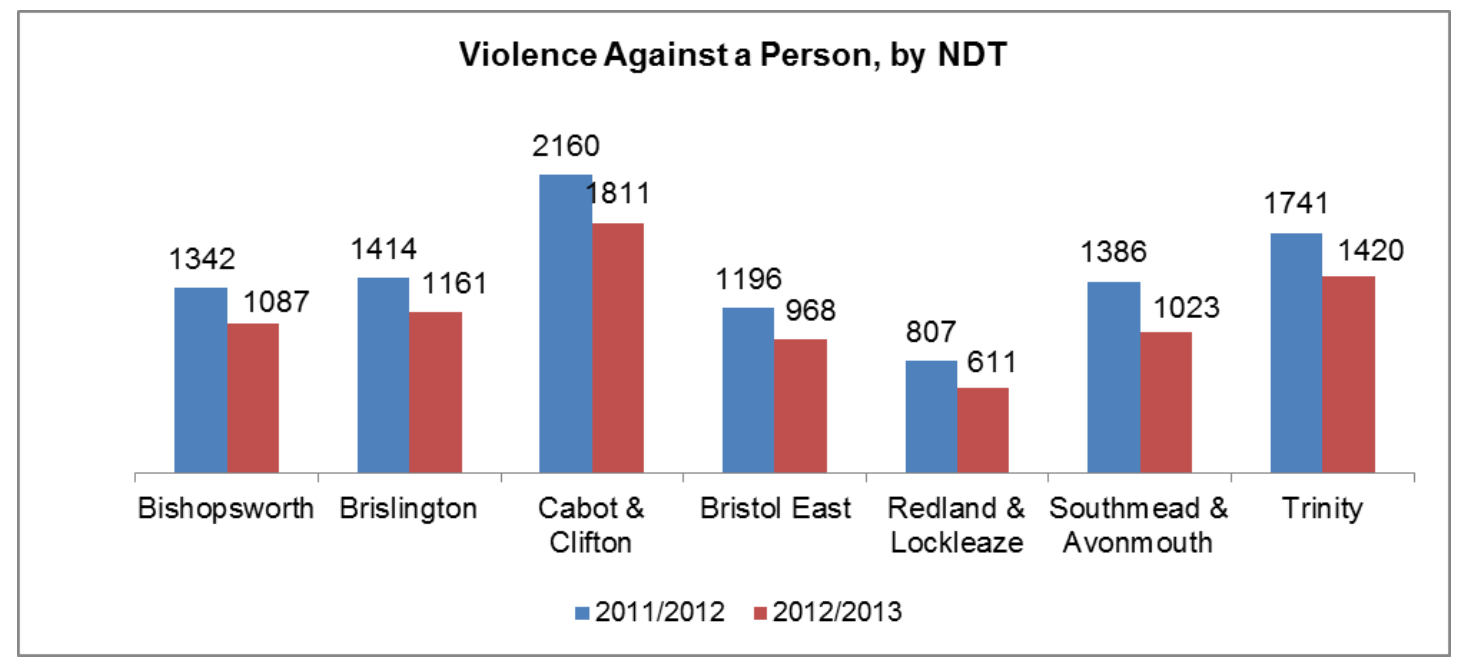

Figure 6: Violence Against a Person by $N D T^{40}$

Having established links between the night time economy and violent crime, a Taxi Marshal service has been established to maintain a well-managed, orderly and fair queuing system for two city centre taxi ranks. On average, 2,500 people per weekend are assisted through the taxi ranks by the marshals.

A set of preferred operating standards for licensed premises is currently being proposed, with the aim of improving safety and decreasing the chances of violent incidents. It is envisaged that the operating standards are published and adopted by licensed venues across the whole city. This project is still in its infancy. The Gold Standard Taxi Driver status is now mandatory for all new Bristol taxi drivers. The aim is to improve overall standards and promote engagement between Bristol City Council and the taxi trade. At present, there are 301 licensed taxi drivers who have completed the training for the Gold Standard. This represents $16 \%$ of all licensed taxi drivers in the City $(1,855)$.

Bristol City Centre has been awarded, for the third year, the prestigious national Purple Flag as a well-managed and vibrant place to visit and enjoy. The award followed a joint bid by Bristol City Council, Avon and Somerset Police and Destination Bristol. The Purple Flag Award scheme is awarded by the Association of Town Centre Managers. The

\footnotetext{
${ }^{40}$ Figures measured between1st August 2012 to 31 st July 2013
} 
award recognises the wide choice of entertainment and leisure attractions and the range of restaurants, hotels, bars and clubs. The aware also recognises the requirement for strong partnership working towards making the city centre safer. A recent inspection of the city centre established that standards have been maintained and improved. The continued introduction of preferred operating standards is being used with licensed premises, to improve safety and decrease the chances of violence.

In order to build on the partnership work established to deliver Purple Flag, discussions are taking place with a view to setting up a Late Night Business Improvement District (BID) to support the management of the night time economy.

\section{Recommendations}

- Introduce the minimum operating standards for licensed premises to all areas of Bristol (initially target problem areas and premises).

- Continue to develop the actions being used to decrease the re-offending rates of violent offenders in the night-time economy.

- Increase participation of licensed premises in the Purple Flag activities to provide a common platform for engagement with businesses working towards a positive outcome for the area.

- Investigate any links to offender management programmes which are working with offenders/potential offenders e.g. IMPACT, Troubled Families and Family Intervention Projects.

- Active partnership working with neighbourhood inspectors to reduce violent crime outside of City Centre.

- Develop a Late Night BID with partners to support the management of the night time economy in the Purple Flag area. 


\section{Domestic Violence and Abuse}

\section{Overview}

In February 2013, the Home Office reviewed the definition of domestic violence and abuse. The term 'domestic violence' constitutes 'any incident or pattern of incidents of controlling, coercive, or threatening behaviour, violence or abuse between those aged 16 years or over who are or have been intimate partners or family members regardless of gender or sexuality'. ${ }^{41}$ This can encompass, but is not limited to, psychological, physical, sexual, financial, and emotional abuse.

Research conducted in 2013 shows that in Bristol, the estimated total cost of domestic violence and abuse cases is £58.1 million per annum which is comprised of physical and mental health care, criminal justice, social services, housing and refuges, legal services, and lost economic output costs. ${ }^{42}$ In addition, human and emotional costs were estimated to be £91.5 million.

There are a number of victim support services in Bristol that aim to increase confidence in reporting and provide support to those experiencing domestic violence and abuse. As under reporting is an issue in this area the number of victims seen by support services has been included to further our knowledge of the need across the city.

\section{Performance}

There were 6178 incidents reported to the Police in 2012/2013, compared to 7,165 reported incidents in the previous year. Breaking down the 6,178 figure into crimes and incidents, 2986 cases were classified as crime (48\%) whilst the remaining $(3,192,52 \%)$ were also reported to the Police and classified as non-crime. The overall number of cases represents a $5 \%$ reduction in the reported incidents to the Police. Figure 7 below shows the trend of domestic violence and abuse in the last nine years.

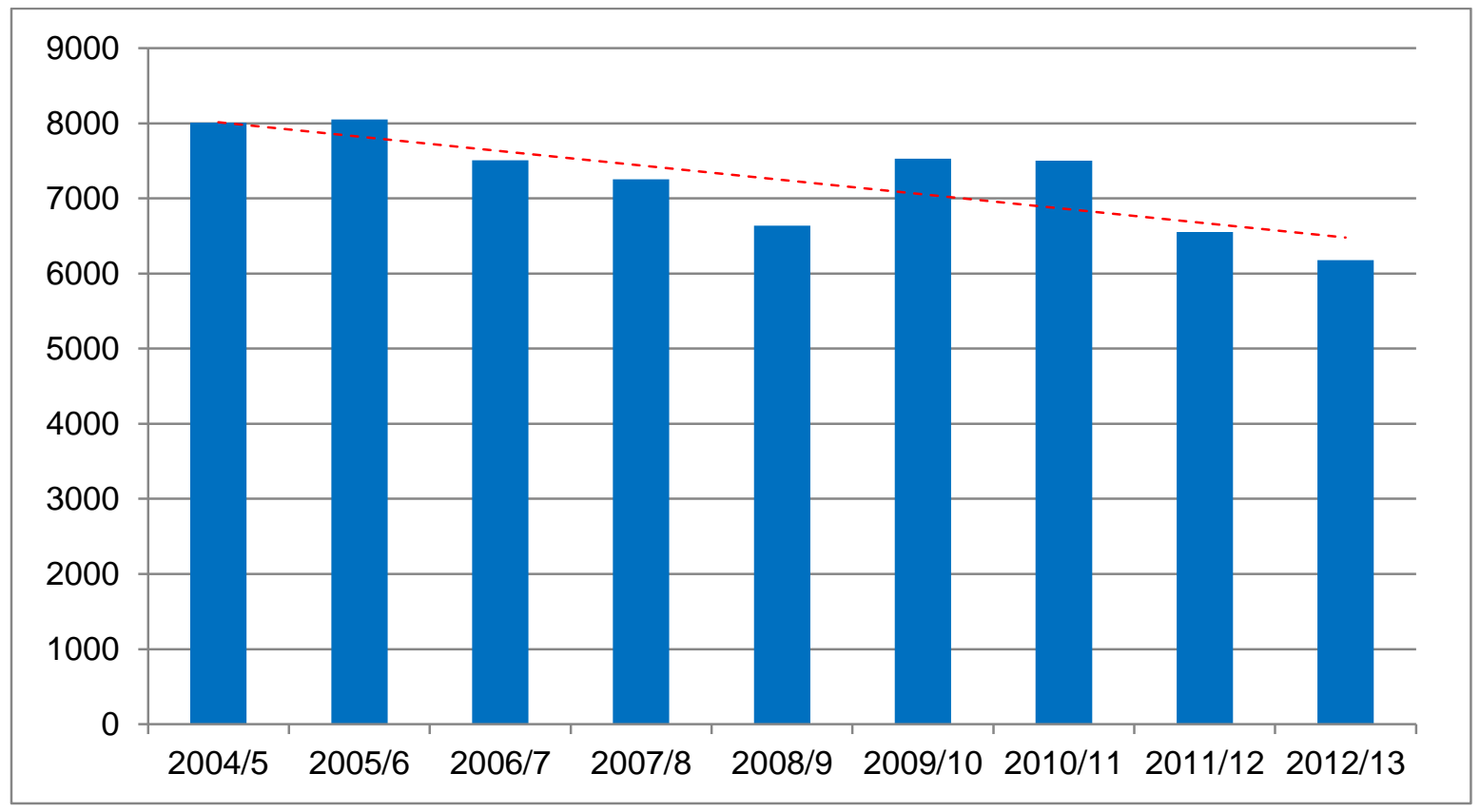

Figure 7: Domestic Violence and Abuse Trend 2004/2005 - 2012/2013

\section{Victim}

In $2012 / 2013,81 \%$ of the victims were female $(1,991)$, in line with expectation that the vast majority of victims reporting domestic violence and abuse are female. There were 2,917 (43\%) incidents in which children are linked to the domestic violence and abuse cases. There is no core cities comparison data for domestic violence and abuse available from the Police.

\footnotetext{
${ }^{41}$ Home Office Circular 003/2013, 'Circular: New Government Domestic Violence and Abuse Definition' (14 ${ }^{\text {th }}$ February 2013)

42 'Costs for Domestic Violence Per Local Area', available at:

http://www.avaproject.org.uk/media/60461/costs\%20of\%20dv\%20by\%20local\%20authority.pdf (last accessed: 23rd July 2013). Professor Sylvia Walby of Lancaster University.
} 
Under-reporting: It is widely acknowledged that domestic violence and abuse is underreported by victims. The British Crime Survey 2010/2011 estimated that $23.5 \%$ of adults aged $16-59$ years experienced domestic violence and abuse. Using this percentage as an estimate, it is projected that 33,119 adults suffered from domestic violence and abuse in Bristol. Actual figures show 2674 people reported to the Police in 2012/2013, which is remarkably lower than the projection of domestic violence and abuse cases in Bristol. This is illustrated by figure 8 below which shows the number of domestic violence and abuse victims in contact with the Police:



Figure 8: Proportion of Domestic Violence and Abuse Victims Reported or Unreported to the Police in Bristol $\underline{2012 / 2013}$

The majority of the victims who reported to the Police fall under aged $25-34$ years (32\%) and aged $35-44$ (33\%) years, as detailed by Table 8 below.

\begin{tabular}{lc}
\hline Age Group & Number of Victims \\
\hline 16 and under & 23 \\
$17-24$ & 329 \\
$25-34$ & 868 \\
$35-44$ & 617 \\
$45-54$ & 499 \\
$55-64$ & 204 \\
$65+$ & 134 \\
Total & 2,674 \\
\hline
\end{tabular}

\section{Table 8: Age Group of Victims}

The wards which have the highest reported domestic violence and abuse cases in Bristol are:

- $\quad$ Lawrence Hill - 263 victims

- Avonmouth - 213 victims

- Hartcliffe - 172 victims

- Filwood - 166 victims

- $\quad$ Cabot - 153 victims

It can be concluded that at least three out of ten domestic violence and abuse victims who have reported to the Police live in the wards noted above. In particular, Lawrence Hill, Hartcliffe and Filwood wards are considered as deprived wards in Bristol, although domestic violence and abuse is not a geographical issue and happens across the city. This data reflects the numbers of victims who have reported to the Police only. 


\section{- Repeat Victimisation}

In Bristol, 22\% of the victims last year were considered to be repeat victims by the Police. Therefore, two out of ten domestic violence and abuse victims reported violence on more than one occasion.

\section{- Mental Health and Domestic Violence}

There is a strong link between domestic violence and abuse, causing mental health issues. Research shows that domestic violence and abuse causes significant mental health problems and the more severe or frequent the abuse, the greater the risk of mental distress.

Joint research between King's College London and the University of Bristol found that men and women with mental health disorders, across all diagnoses, are more likely to have experienced domestic violence and abuse than the general population. Compared to women without mental health problems, women with depressive disorders were around two and a half times more likely to have experienced domestic violence and abuse over their adult lifetime (prevalence estimate 45.8\%); women with anxiety disorders were over three and a half times more likely (prevalence estimate 27.6\%); and women with post-traumatic stress disorder (PTSD) were approximately seven times more likely (prevalence estimate $61.0 \%$ ). ${ }^{43}$ Men with all types of mental disorders were also at an increased risk of becoming a victim of domestic violence and abuse. However, prevalence estimates for men were lower than those for women, indicating that it is less common for men to be victims of repeated severe domestic violence and abuse.

Multi Agency Risk Assessment Conferences (MARACs) - MARACs agree upon safety plans for victims at high risk of serious physical injury or death from domestic violence and abuse. The CAADA DASH Risk Identification Checklist is used to identify high risk victims. This checklist covers issues such as levels of fear, use of weapons, threats to kill, sexual violence, depression and suicidal thoughts. In 2012/2013, there were 23 meetings held, at which 595 cases were discussed by practitioners. Of these cases, $133(22 \%)$ repeat cases were discussed. The reported cases also concerned 695 children in households across Bristol. Of the cases discussed at MARAC, $54 \%$ of the referrals came from Avon \& Somerset Police, whilst the remaining were referred to by partner agencies.

Bristol MARACs receive a very high number of referrals. For this reason, it has been necessary to introduce a pre-MARAC process to discuss referrals that are assessed at the lower end of high risk. In 2012-13, 576 cases were discussed at pre-MARAC, 351 of these were not referred on to MARAC. This means that there was a total of 946 high risk victims discussed at MARAC or pre-MARAC during the year. MARAC's referrals come from a range of sources, which are illustrated in the chart below:

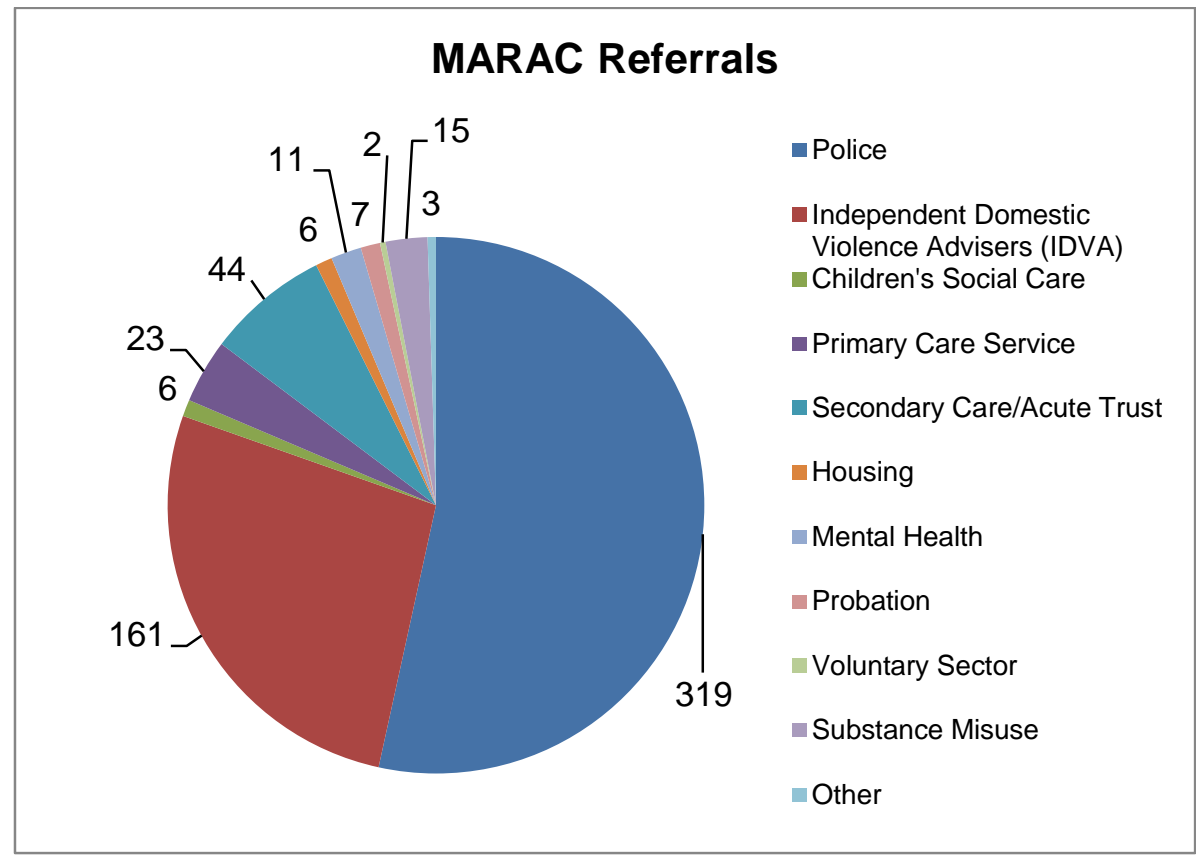

Figure 9: MARAC Referrals

43 Trevillion, K. et al, 'Experiences of Domestic Violence and Mental Disorder: A Systematic Review and Meta-Analysis', available at: http://www.plosone.org/article/info\%3Adoi\%2F10.1371\%2Fiournal.pone.0051740 (last accessed: 23 ${ }^{\text {rd }}$ July 2013). 


\section{- Victim Support Services and Community-based Services}

The following table shows the main support services provided to domestic violence and abuse victims in Bristol in 2012/2013:

\begin{tabular}{|c|c|c|}
\hline Name of services & Beneficiaries & Outcomes \\
\hline Resettlement Service & $\begin{array}{ll}\text { - } & 620 \text { adults } \\
\text { - } & 114 \text { children }\end{array}$ & \\
\hline $\begin{array}{l}\text { Independent } \quad \text { Domestic } \\
\text { Violence Advisors (IDVA) } \\
\text { Victim Support }\end{array}$ & $\begin{array}{l}\text { - } 92 \text { service users } \\
\circ \quad 48 \text { users were supported } \\
\text { through the MARAC process } \\
\circ \quad 32 \text { users were supported } \\
\text { through the criminal justice } \\
\text { process. }\end{array}$ & $\begin{array}{l}\text { - Specialist staff funded to work } \\
\text { with high risk victims and } \\
\text { survivors and develop safety } \\
\text { plans. } \\
\text { - } 46 \text { users felt safer at the end of } \\
\text { the intervention. }\end{array}$ \\
\hline
\end{tabular}

- 75 clients received a service and were risk assessed.
- Safety plans were put in place.

- All service users reported an increase in well-being and selfempowerment

- 74 reported an improvement in their safety.

\section{IDVA A\&E}

Survivor Groupwork

- 229 groupwork sessions

- 132 women completed the course.

Bristol Northern \&

Southern Arc Community

Support Service
- 261 referrals

$$
\text { - } 240 \text { women }
$$$$
\text { - } 21 \text { men }
$$

- $112(43 \%)$ were supported through the MARAC process.
- 250 women reported that they had increased confidence

- 264 women reported that they had increased knowledge about domestic violence and abuse.
The satisfaction level of the service users was as follows:

- $94 \%$ of service users felt safer in their home and community

- $83 \%$ of service users were supported to remain in secure accommodations

- $92 \%$ of service users reported an improvement in their health and wellbeing

- $85 \%$ of service users reported an improvement in their economic status
Safe House Provision

\section{Table 9: Support Services and Community-based Services}

- $\quad 33$ bed spaces and generally operating at full capacity throughout the year.

- 119 women and 53 children were supported by the Safe House Service. 
Next Link provides many services to women experiencing domestic violence and abuse in Bristol. In 2012/2013, they recorded 2,946 enquiries and supported 2,333 families. They also provided face-to-face advice to 104 families and telephone advice to 387 victims.

Referrals were made by telephone at the Next Link's public office, where women were asked about their situation, the number of children they have with them, what areas of the city are unsafe for them, and whether they require a safe house, the resettlement service, outreach support, crisis response service or the South Asian Crisis Service.

Next Link also have six safe houses in the city including a dedicated house for BME women and children, a house for single women and a block of self-contained units. In 2012/2013, they received 499 referrals and they housed 119 families with 88 children.

Next Link data shows that there has been a significant increase in demand for their domestic violence and abuse service. The increase in victims seeking help has risen by $24 \%$. Next Link consider the reason for these increases to be both negative and positive. It has long been held that domestic violence and abuse tends to increase during an extended period of recession and there is a statistical link between the economic downturn and an increase in violence towards women. Women often bear the brunt of their partner's anger when the family income is reduced while at the same time they have the major responsibility for the caring of children and other dependent family members. Social isolation and poverty also are much more common in women which can mean they are less likely to seek help because of their worry about what will happen to their children or to other people that rely on them for their day-to-day needs.

Other services provided to the victims of domestic violence and abuse include the following: IRiS Primary Care Service, BME Crisis Support, Frenchay A\&E IDVA, Troubled Families DVA Support, Police Safeguarding Unit, MARAC Support, Telephone Helpline, Crisis Response, Children and Young People Services (CYPS) Safe House and Resettlement Services.

\section{Offender}

Figure 10 shows that offenders of domestic violence abuse will often repeat this behaviour over a period of time. However, the majority of offenders are only recorded against one offence. This may be due to under-reporting or may be due to intervention from authority helping to prevent re-occurrence of offending.

\begin{tabular}{|c|c|}
\hline & Number of Incidents by Perpetrators \\
\hline Not recorded & 157 \\
\hline 1 incident & 1096 \\
\hline 2 incidents & 474 \\
\hline 3 incidents & 118 \\
\hline 4 incidents & 149 \\
\hline 6 incidents & 92 \\
\hline 8 incidents & 28 \\
\hline 9 incidents & 24 \\
\hline 10 incidents & 1 \\
\hline 12 incidents & 18 \\
\hline 15 incidents & 3 \\
\hline 16 incidents & 5 \\
\hline 24 incidents & 4 \\
\hline 30 incidents & 1 \\
\hline
\end{tabular}

Figure 10: Proportion of Domestic Violence and Abuse Victims Reported or Unreported to the Police in Bristol

About $83 \%(1,801)$ perpetrators were male. The ethnicity data was not fully recorded.

In terms of the Police's suspect risk rating, a large portion of the perpetrators $(44 \%, 961)$ were considered as medium risk. This is followed by low risk perpetrators $(30 \%, 652)$ and high risk perpetrators $(10 \%, 226)$. The risk rating is defined below:

- Low risk - Current evidence does not indicate likelihood of causing serious harm. 
- Medium risk - There are identifiable indicators of risk of serious harm. The offender has the potential to cause serious harm. The offender has the potential to cause serious harm but is unlikely to do so unless there is a change in circumstances, for example failure to take medication, loss of accommodation, relationship breakdown, and drug or alcohol misuse.

- High - There are identifiable indicators of risk of serious harm. The potential event could happen at any time and the impact would be serious.

There are a total of 27 questions asked in total to determine the risk, with regard to the following factors:

- Injury

- Financial issues

- Substance misuse

- Breach of bail, injunction

- Children and pets

- Criminal history

- First and repeat offence

- Mental health and suicidal tendency

Integrated Domestic Abuse Programme: The Integrated Domestic Abuse Programme (IDAP) is a Probationaccredited programme for working with domestic violence and abuse offenders being supervised by the Probation Service. The programme tackles issues such as the misuse of power and control and is designed to help offenders stop their violence. Support is also offered for the partners of men attending IDAP. In 2012/2013, 54 offenders successfully completed the programme in Bristol.

Voluntary Perpetrator Programme: The 'Stopping Violence Programme', is a voluntary perpetrator programme, which was established in October 2010. This is aimed at men who are seeking help to change violent, controlling, or harmful behaviour (all referrals are effectively self-referrals). Partners/ex partners of these men are also offered support from a women's safety worker. In 2012/2013, 28 men enrolled in the programme and 19 of them successfully completed the programme.

The Women's Safety Worker also offered a service to all female partners and/or ex partners of the men who were offered and accepted a place in a programme, with 20 accepting support.

Prevention Programme: The Violence against Women and Girls (VAAWG) Public Health Team has been recently integrated into Safer Bristol. Their focus is on using education, campaigns and training to both prevent violence and abuse and ensure that victims are supported. Specific projects include supporting schools to develop relevant policies and lesson plans exploring VAAWG, ensuring prisoners identifying as perpetrators feel supported to change their behaviour and developing a toolkit for professionals working with those with learning difficulties as this is seen as a vulnerable group.

\section{Location}

The Quality of Life Survey 2012 results show areas in which respondents believe domestic violence is a private matter in Bristol. In particular, residents from the deprived wards, such as Filwood (32\%) and Lawrence Hill, and Hartcliffe agreed with this statement (all 23 - 24\%). 


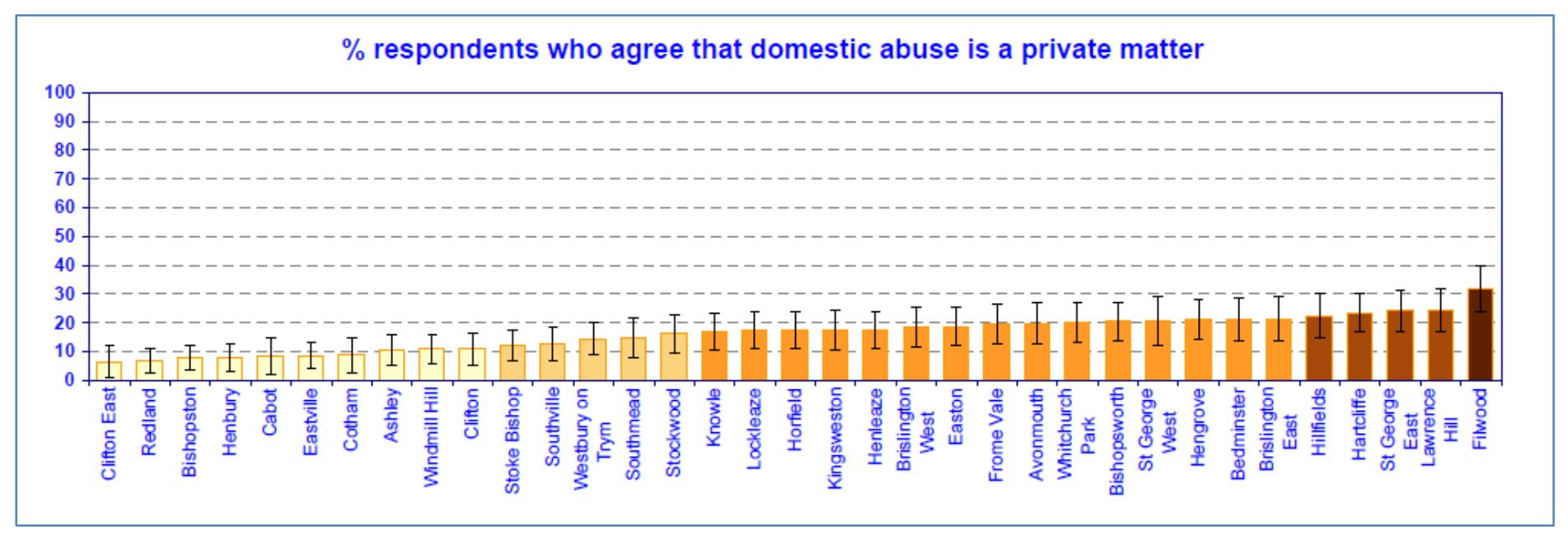

Figure 11: \% of Respondents who agree that Domestic Abuse is a private matter

;tol. By thinking that domestic violence and abuse is a private matter, it seems to suggest that the violence should remain hidden. It is also important to note that domestic violence and abuse can happen across the City as it is not linked to a locality factor, such as area of deprivation.

\section{Recommendations}

- Review and improve support available for victims of domestic violence and abuse with complex needs, for example enduring mental health needs or substance misuse issues.

- Undertake an in-depth needs analysis into the extent of domestic violence and abuse in Bristol, including a review of referral thresholds and accessibility of services.

- Build on current initiatives to increase reports from disabled and lesbian, gay and bisexual victims. This is in line with the Council's Equalities Action Plan.

- Review activities to support victims and increase their resilience to further domestic violence and abuse, and review interventions for perpetrators.

- Performance issues, particularly on data collection by the domestic violence and abuse support agencies, will need to be considered, in line with the VAAWG recommissioning process, which will commence in autumn 2013.

- $\quad$ Consider alternatives to benchmark our performance with core cities.

- $\quad$ Support the review of pre-MARAC process to enable the partnership to respond to high risk victims.

- MARAC to continue reviewing referral sources to ensure cross partner involvement

- Compare the cohort of perpetrators with other types of crime, to see whether there is any overlap, to facilitate joint approach between stakeholders. 


\section{Sexual Violence}

\section{Overview}

According to the Home Office classification, 'sexual offences' constitute soliciting sexual services in a public place, sexual assault, rape, attempt rape, sexual exposure, sexual grooming, sexual activities with children under 13 years and controlling prostitution for gain.

From September 2009, a dedicated Police team to tackle rape and sexual assault was put in place in Bristol called 'Operation Bluestone'. The team has increased its capacity which has enabled more reporting channels to encourage the victims to come forward to report sexual offences.

\section{Performance}

The British Crime Survey 2010 estimated that only $11 \%$ of victims of sexual offences reported incidents to the Police. This is the latest estimate data available on sexual offences. In 2012/2013 there were 834 sexual offences in Bristol, $56 \%$ (467) of which were of a serious nature. Reported sexual offence figures in Bristol decreased by $24 \%$ between 2011/2012 and 2012/2013, which suggests that victims are continuing to fail to report, as depicted by Figure 12 below.

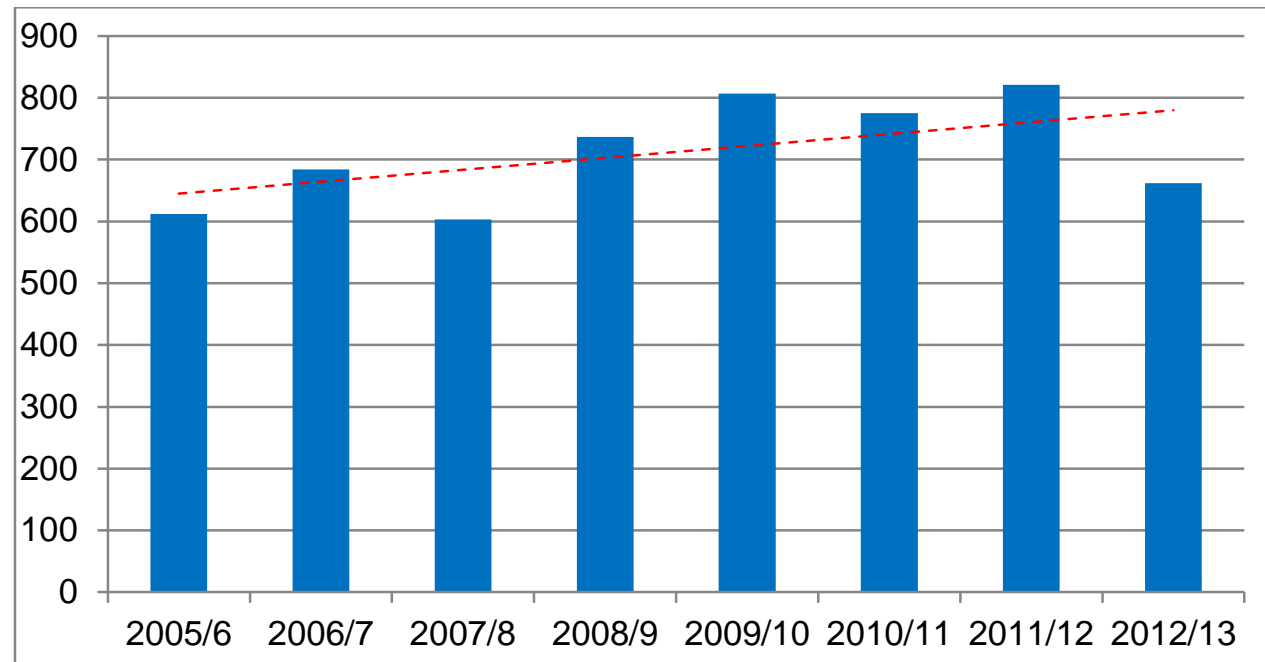

Figure 12: Sexual Offences in Bristol 2012/2013

In terms of serious sexual offences, 135 offences were detected (29\%), whilst for rape, 49 offences were detected $(25 \%)$. The investigation for rape offences may take longer than other crime types depending on the length and complexity of the cases (between 6 and 12 months, with an additional three months waiting for the Crown Prosecution Service (CPS) to prepare for prosecution, unless the offenders were considered as dangerous offenders, which could trigger emergency procedures).

Compared to other core cities in England, Bristol is ranked the third highest for levels of reported sexual offences per thousand population, as illustrated in Table 10 below. Whilst this indicates that the reporting of such offences is moving in the right direction in Bristol, more work needs to be done to increase awareness of the people to report such offences when they occur.

\begin{tabular}{lc}
\hline Core Cities & Rate Per Thousand Population \\
\hline Sheffield & 0.6 \\
Newcastle & 0.9 \\
Liverpool & 1.1 \\
Leeds & 1.2 \\
Birmingham & 1.2 \\
Bristol & 1.3 \\
Nottingham & 1.5 \\
Manchester & 1.7
\end{tabular}

Table 10: Sexual Offences Core Cities Comparison 
Female Genital Mutilation (FGM) is also considered under the sexual violence strand. It includes procedures that intentionally alter or cause injury to the female genital organs for non-medical reasons. The procedure has no health benefits for girls and women and it can cause severe bleeding and problems urinating, and later cysts, infections, infertility as well as complications in childbirth and increased risk of new-born deaths.

The FGM issues in Bristol are overseen by the FGM Delivery group. The group consists of NHS Bristol, Bristol Community Health, University Hospitals, Bristol and North Bristol Trust. In the UK, there are around 24,000 girls under 15 years who are at risk of FGM in the UK, and between 2009 and 2012, 24 FGM offences were recorded by the Police in Bristol. Bristol City Council Children and Young People Services (CYPS) also recorded 11 cases.

The Female Genital Mutilation Act was introduced in 2003 and came into effect in March 2004. The Act makes it illegal to practice FGM in the UK and has a penalty of up to 14 years in prison and/or a fine.

Victim

The demographic patterns of the victims of sexual violence are:

- Age - A large portion of the victims came from aged 15 years and under, highlighting the vulnerability aspect of this crime type because of the age factor $(27 \%, 230)$.

- Gender - Six out of ten victims were female.

- Location $-32 \%$ of the victims (207) live in Eastville ward.

- Ethnicity $-45 \%$ (377) of the victims came from the White British background, whilst the ethnicity of the other 394 victims was not recorded.

Avon \& Somerset Police recently conducted a Rape and Serious Sexual Offences (SSO) Victimisation Review. The review shows the following findings which may help in reducing victimisation:

- The majority of victims of rape and SSO do not seek contact with any form of support service.

- Victims are more likely to be students or unemployed. The marital status of victims is predominantly single.

- National data suggests that females from households in the lowest income bracket (under $£ 10,000$ per year) showed an increased risk of victimisation (3.8\%) as did full time students (6.8\%), and the unemployed (3.8\%).

- Factors relating to household location and housing tenure were found to be related to the risk of victimisation. Prevalence rates were higher among females in the 'City Living' Output Area Classification category, people living in flats or maisonettes, those living in an urban area and in rented accommodation

- Victims are more likely to be assaulted by someone known to them. This may be a reason why a significant proportion of victims do not contact the Police, for fear of reprisals.

\section{Under-reporting}

Under-reporting issues will be improved through partnership work between the Police (Operation Bluestone) and third sector agencies such as Independent Sexual Violence Advisors (ISVA) and Bristol Rape Crisis Centre. This is particularly important as an analysis of violent offences against sex workers in Bristol identified that sex workers are 167 times more likely to be a victim of rape and 67 times more likely to be a victim of attempted rape than a non-sex worker female in Bristol.

\section{- Victim Support Services}

Independent Sexual Violence Advisors (ISVA) specialist staff are co-funded by Safer Bristol to work with survivors and victims of sexual violence by helping them to pursue justice and find closure through the court system. In 2012/2013, 187 adult victims of sexual abuse and 59 children were supported by the service in Bristol.

Bristol Rape Crisis provides specialist telephone and face-to-face support services for women and girls who have experienced sexual violence at any point in their lives. In 2012/2013, the agency received 539 calls through its helpline, with 56 individuals who received on-going support from the centre.

Avon and Somerset Police are currently in the process of improving their approach to tackling on-street prostitution through the 'street sex workers initiative'. The safeguarding of on-street sex workers is a current priority, with a risk assessment of known sex workers currently being developed to help identify the most vulnerable and also to try to divert those of a lower risk away from street sex work.

One25 Street Sex Work Options Project (SSWOP) offers a professional befriending service to women who are or have been engaged in street based sex work. In 2012/13 the project worked with 109 women. 68 women engaged 
with an exit plan, 63 women were offered post exit support and 86 were being provided some accommodation support. Furthermore, 16 women exited street sex work, 10 completed a drug/alcohol detox programme and 27 women were on a drug/alcohol stabilisation programme.

The Bridge programme is one of the first Sexual Assault Referral Centres (SARC) to open in South West England and provides comprehensive support to women, men and children of the Avon and Somerset area.

The Sexual Violence MARAC meets monthly and through a multi-agency conference they risk assess and safeguard individuals who are vulnerable to repeat sexual assault. There were 62 cases discussed at the sexual violence MARAC in 2012/2013.

\section{Offender}

To address the perpetrators of sexual offences, the following programmes are currently being undertaken in Bristol:

- IRiS, the integrated offender management approach being used to manage dangerous violent and sexual offenders who pose a high risk of harm and re-offending. IRiS consists of a team of professionals from various organisations such as Probation, Police, Prison and Mental Health. As at December 2012, there were 176 live cases being intensely managed through IRiS. From July 2012 to August 2013, 51 offenders have been successfully migrated out of IRiS.

As of September 2013, IRiS has 190 cases where they are shared between the Police and the Probation. The demographic information of these offenders is as follows:

- Gender - 95\% (184) are male.

- Ethnicity $-63 \%$ of the managed offenders are White British (110), followed by Black Caribbean $(25,14 \%)$.

- Age - A large portion of the offenders come from the age group $25-34(71,37 \%)$.

- Index offence - Looking at the index offence, $18 \%$ were involved in robbery (34), assault leading to grievous bodily harm $(23,12 \%)$ and rape $(17,9 \%)$.

- Location - The majority of the offenders under IRiS $(62 \%, 119)$ are currently in prison. 71 offenders are currently in the community.

All agencies are working towards a single risk management plan under the Joint Risk Management Plan, to avoid duplication and make the process more efficient.

- Juvenile Offenders - Be Safe is a multi-agency, multi-disciplinary partnership service in Bristol managed by North Bristol NHS Trust (NBT) with staff from NBT, CYPS Social Care, Bristol YOT, and Barnardos. The service works with children and young people aged eight to 17 years where there are concerns about their problematic/harmful sexual behaviour and offers advice, consultation, and training to professionals. It also provides direct assessment and intervention services to children, young people and their families. Be Safe is accountable to the Be Safe multi-agency partnership group with representatives from each of the agencies seconding staff to the service as well as to Avon and Somerset Police, and to the Bristol Children's Safeguarding Board. Be Safe was involved with seven young people either through direct work or providing consultation involved with the YOT in 2012/2013.

- Kerb crawling - A total of 372 kerb crawling offences were recorded in 2012/2013. The breakdown of the sanction is displayed within the following chart: 


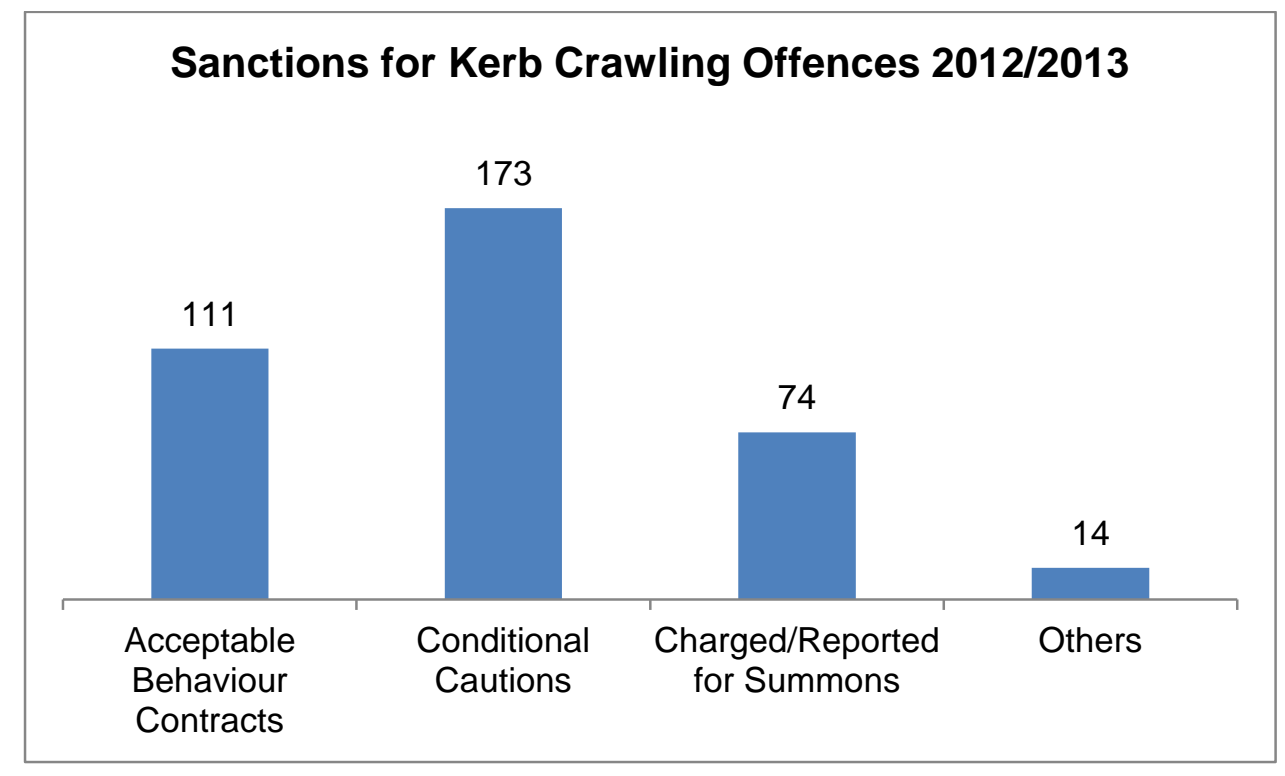

\section{Figure 13: Sanctions for Kerb Crawling Offences}

In addition, 193 soliciting for prostitution were recorded within the same period of time. Street warnings were given to 183 offences, whilst nine were given conditional cautions and one was charged for the offence.

\section{Location}

On-street sex markets: The top five city-wide hotspots for sexual offences are all located around local sex markets in the Trinity Neighbourhood Policing Area (NPA) and Bristol East NPA. A fortnightly tactical assessment produced for Operation Bluestone now identifies crimes committed against known sex workers in Bristol. All offences including sexual offences committed against sex workers are geographically mapped in order to help task and deploy resources used to tackle vice-related crimes. The dedicated Vice Officer, who is now part of Operation Bowler (looking at wider street crime, street sex work and anti-social behaviour) is made aware of victims of crime who are sex workers and of current hotspots for offending.

\section{Recommendations}

- Ensure support services are promoted and relevant for victims of recent sexual assault and more historical sexual assault.

- Continue interventions with perpetrators of sexual offences.

- Undertake more outreach with women and men, girls and boys who are vulnerable to sexual exploitation and assault, and promote availability of support services to encourage increased reporting.

- Ensure campaigns and information to prevent sexual offences place the blame for such offences on the perpetrator. Monitor whether this increases the likelihood for victims to report incidents.

- Further develop the IRiS scorecard to assist in the evaluation of the effectiveness of the approach.

- Safer Bristol to support the extension of IRiS pilot to enable effective management of offenders in Bristol.

- Consider having a dedicated analytical support for IRiS to put together offender profiles with detailed offence and intelligence précis, and assist with the use of the Buddi GPS tagging system 


\section{Human Trafficking}

\section{Overview}

The commonly accepted definition of 'human trafficking' by governments, law enforcement bodies, and agencies derives from the UN Protocol to Prevent, Suppress and Punish Trafficking in Persons (commonly referred to as 'the Palermo Protocol'). According to the Article 3, human trafficking means:

'The recruitment, transportation, transfer, harbouring, or receipt of persons, by means of a threat or use of force or other form of coercion, of abduction, of fraud, of deception, of the abuse of power, or of a position of vulnerability, or the giving or receiving of payments or benefits to achieve the consent of a person having control over another person, for the purpose of exploitation.

Exploitation shall include, at a minimum, the exploitation of the prostitution of others or other forms of sexual exploitation, forced labour or services, slavery or practices similar to slavery, servitude, or the removal or organs'.

Various analyses have attempted to estimate the number of victims of labour and human trafficking, and they differ from each other rather significantly. For example, an analysis of 2,770 articles captured by LexisNexis in 2012 found 263 victims of forced labour and human trafficking were identified by the UK media in Britain last year. On the other hand, the United Kingdom Human Trafficking Centre (UKHTC) found 1,186 potential victims of forced labour and trafficking in 2012. The sexual element is the most commonly reported motivation under the human trafficking agenda.

The Police recently undertook a three-month intelligence capture in order to generate a baseline snapshot across the force area. During this exercise, 53 information reports were received, where 29 cases of sexual exploitation, nine labour exploitation, four forced marriage, and five immigration cases were identified, including six unknown causes.

Nationally, data is gathered on trafficking victims who are identified through the National Referral Mechanism (NRM). The NRM is a system where agencies classified as first responders can refer people if they show indicators that they could have been trafficked. Decisions on whether they are trafficking victims are made by UK Human Trafficking Centre and the Home Office. Extra help is available to trafficking victims if they are in the NRM and have been identified as a victim.

In 2012, there were $25 \%$ more victims referred than in 2011 , and in the first three months of 2013 , there is a $37 \%$ increase from referrals during the same period in 2012. The motivations behind human trafficking offences are illustrated by the chart below:

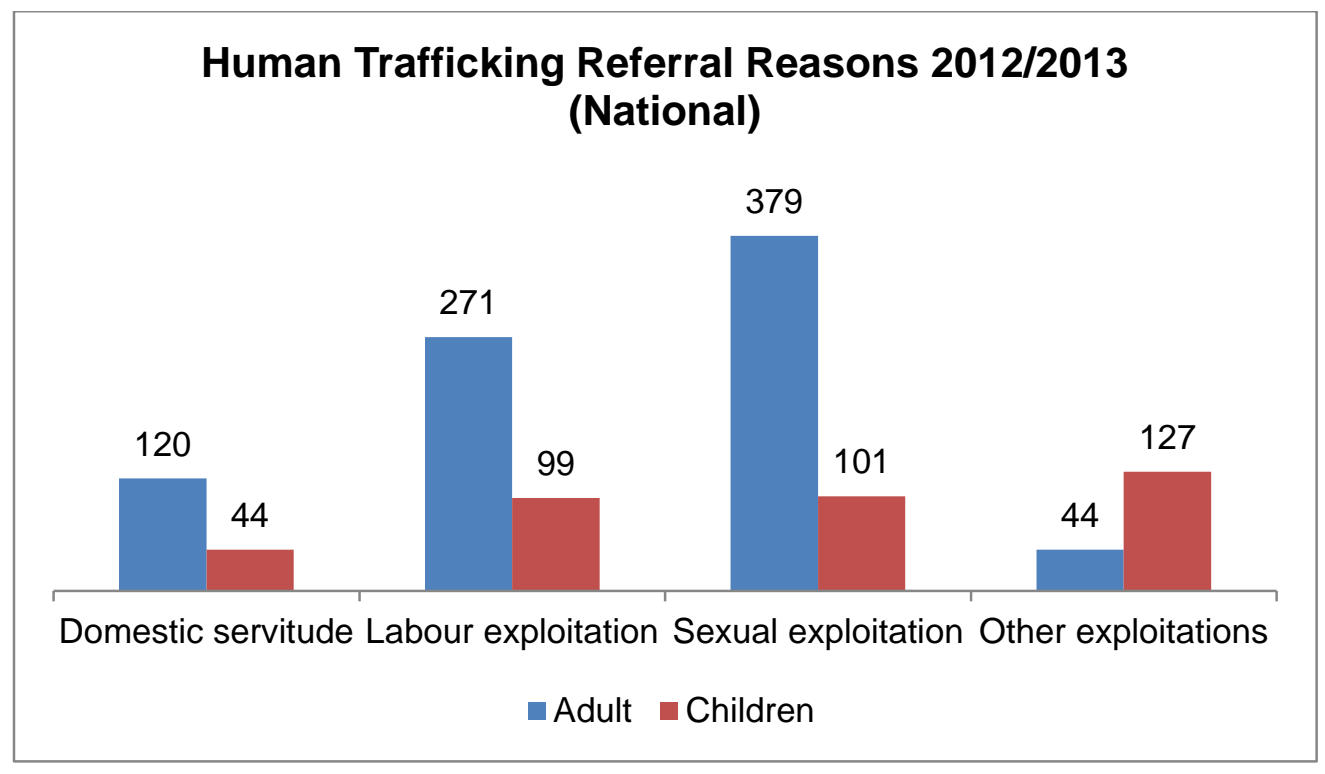

Figure 14: Human Trafficking Reasons 2012/2013 
The countries with the highest number of known trafficking victims are Nigeria, China, Czech Republic, Romania, Hungary, Slovakia, Albania, Ghana, Uganda and Vietnam. ${ }^{44}$ In 2010 research was undertaken in off-street prostitution sector to identify potential victims of sexual exploitation trafficking which identified around 30,000 women were working within this sector, of whom 17,000 were migrant women. Out of the migrant women 2600 were considered to be trafficked, $80 \%$ of whom were from Asia and 20\% from Eastern Europe. ${ }^{45}$

\section{Performance}

Bristol is the first European city committed and acting corporately upon its commitment to raise staff awareness on types and the scale of human trafficking as well as safe and effective ways of combating it. At two recent European workshops on human trafficking held in Brussels, Bristol City Council was hailed as an excellent example of good practice. At the recent Human Trafficking conference at Bristol City Council, which was held on $4^{\text {th }}$ July 2013, the NRM referrals showed that there were 27 human trafficking cases in Bristol.

\section{Victim}

Avon and Somerset Police reviewed 53 information reports relating to 27 potential victims of trafficking. Of the 27 potential victims, 18 were of Vietnamese origin and 4 of UK origin, with other victims originating from the Czech Republic, Romania, China, Malaysia and Poland.

A recent research undertaken by the Centre for Social Justice identified that human trafficking is widely under reported due a large proportion of cases not being recognised or reported by UK agencies. Reasons for this include a lack of awareness of the issue in frontline services, minimal training and high levels of fear and reluctance from the victims to come forward, both children and adults.

For victims who do not have immigration status there are additional fears of reporting to statutory agencies for fear of criminalisation, being wrongly identified and even deported. Nevertheless, reporting is increasing year on year. In a bid to increase opportunity for reporting, Bristol's Children's and Adults Safeguarding Policies include trafficking indicators and pathways.

Safer Bristol works closely with Unseen UK to raise awareness of human trafficking amongst agencies. The Salvation Army has a national contract to assist victims that have been through the NRM and are identified victims.

Since the Unseen Safe House was opened in May 2011, 50 women have been accommodated through this route. Of these 50 women, 13 have been moved on to the next step of working with a resettlement worker in Bristol, four are currently living in Bristol and the rest have moved on to other areas of the UK. The Unseen Safe House also takes in people who have been trafficked from other areas of the country.

\section{Location}

It is important to note that the Police will tend to identify victims from the sex markets and cannabis factories as these are crime-related environments, but will have less day to day contact with other workplaces which can be used for trafficking purposes - nail bars, car washes, food outlets, farms and takeaways, although this is not a comprehensive list. Safer Bristol will raise awareness with agencies who are more likely to encounter potential victims in these sectors.

\section{Recommendations}

- Focus on publicity materials aimed at Bristol residents to increase awareness of human trafficking, how to report suspected trafficking cases, and how to get help, through various media.

- Produce case studies to enhance understanding of human trafficking issues, along with its impact on the local community.

- Since there is a strong correlation between human trafficking and sexual offences, explore targeting information and efforts towards areas with high propensity of sexual offences and sex markets.

\footnotetext{
${ }^{44}$ The Centre for Social Justice, 'It Happens Here - Equipping the United Kingdom to Fight Modern Slavery': http://www.centreforsocialjustice.org.uk/UserStorage/pdf/Pdf\%20reports/CSJ Slavery Full Report WEB(5).pdf (accessed: $20^{\text {th }} \quad$ September 2013).

${ }^{45}$ Setting the Record (2012).
} 
- Consider responding to the government proposal on plans to charge non-EU migrants more for NHS care, which could put vulnerable women and victims of sex trafficking at risk. ${ }^{46}$

- Build on partnership opportunities arising from the anti-trafficking conference in July 2013 to increase informal reporting of trafficking for sexual exploitation

- Voluntary sector organisations in the human trafficking field in Bristol to take a proactive approach to facilitate partnership working across other local authorities area to tackle a crime that has no respect for borders.

46 'Victims of Trafficking at Risk Over NHS Charging Plan', available at: http://www.independent.co.uk/news/uk/politics/victims-of-sex-traffickingat-risk-over-nhs-charging-plans-8688788.html (last accessed: $7^{\text {th }}$ August 2013). 


\section{Anti-social Behaviour}

\section{Overview}

There is an increasingly high emphasis being placed by the Government on ASB and methods to tackle it. ASB was defined in the Crime and Disorder Act 1998 as "acting in a manner that caused or was likely to cause, harassment, alarm or distress to one or more persons not of the same household". People's understanding of what constitutes ASB is determined by a series of factors including context, location, community tolerance and quality of life expectations. Often, this understanding is subjective, in that a person may regard an act as anti-social whilst another person may view the same act as acceptable.

The Anti-Social Behaviour, Crime and Policing Bill 2013 is currently being considered in the Committee Stage of prelegislative scrutiny. It is anticipated that the Bill will become law towards the end of this parliament and provisions will be enacted in the autumn of 2014. Safer Bristol has been actively involved in shaping the development of the Bill and responding to queries that have arisen through pre-legislative scrutiny.

ASB in Bristol ranges from low-level activity such as street drinking and hoax calls to more serious types such as drug dealing and violence. The most significant types of ASB in Bristol are disturbance and nuisance, harassment and threats, assault, and domestic disturbance/violence which together account for $88 \%$ of ASB reported to the City's authorities.

ASB occurs all year round in the city however, similar to national trends, offending in Bristol is marked by strong seasonality, with peaks experienced between April - October (typically associated with the summer months, Halloween and Bon Fire Night).

\section{Performance}

Similar to the downward crime trend in Bristol in 2012/2013, levels of ASB reported to the city's authorities (Avon \& Somerset Police, Bristol City Council and Avon Fire \& Rescue) have also decreased by nearly $5 \%$ over the same period with 36,411 incidents reported.

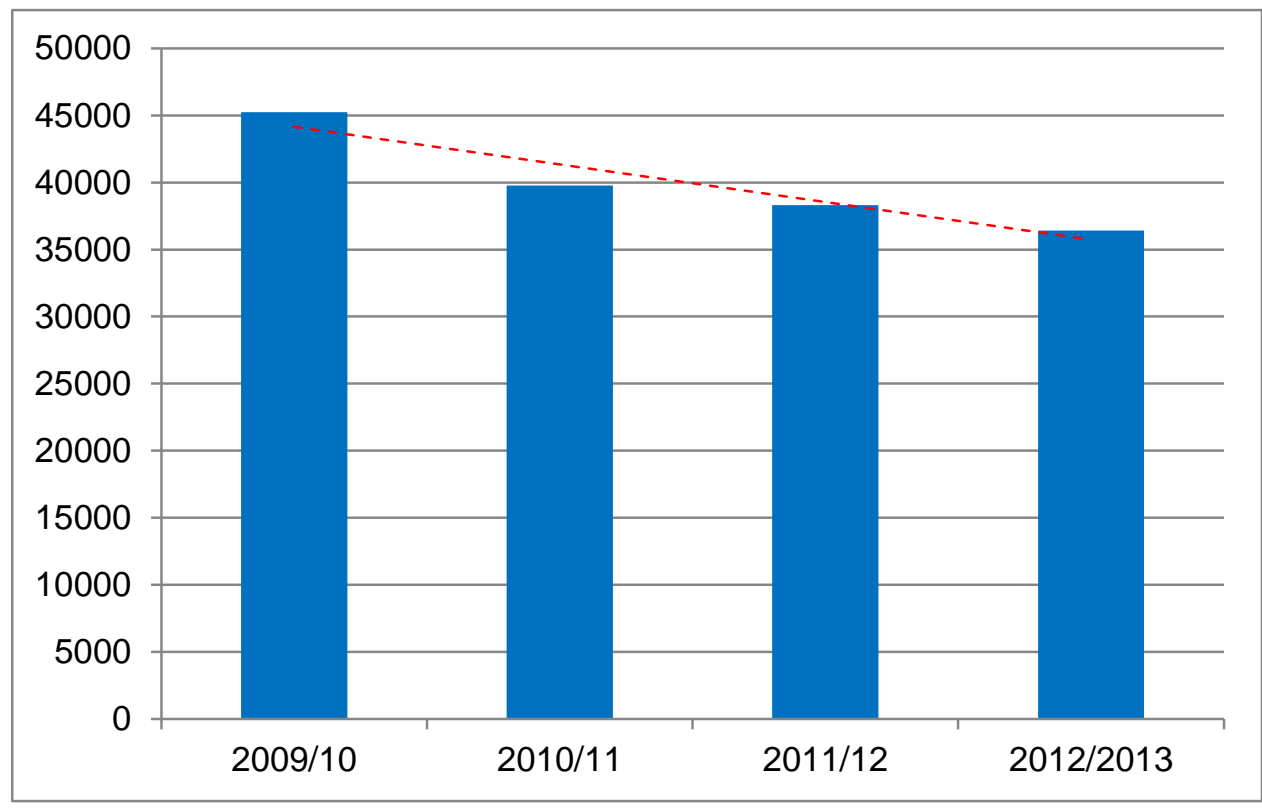

Figure 15: Anti-social Behaviour Incidents Over the Last Four Years in Bristol

Kerb crawler cautions increased slightly in 2012/2013 (62 cautions compared to 56 cautions the year before). However, there was a 36\% decrease in the number of sex workers cautions in 2012/2013 (77 compared to 121 cautions the year before).

Avon Fire and Rescue Services recorded 1,039 anti-social behaviour incidents in 2012/2013. 854 incidents (82\%) were recorded under deliberate fires, whilst the remaining were recorded under deliberate false alarms. 
Bristol City Council, through the Streetscene, Environmental Protection and Housing Teams, recorded 7,419 incidents during the same period. A large portion of these incidents were related to amplified music $(1,939,26 \%)$, domestic noise $(759,10 \%)$ and fly-tipping (750, 10\%).

In addition, overall public perception and confidence in the response to ASB is improving in Bristol. In the Quality of Life Survey 2012, $28.8 \%$ of residents thought anti-social behaviour was a problem in their local neighbourhood. Figure 16 below indicates the year-on-year decrease since the survey began and shows a significant improvement compared with 2005 when $49.2 \%$ of residents felt this issue was a problem locally. Looking at the demographics of the respondents, it is apparent that the number of disabled, LGBT and BME respondents was disproportionately high compared to other respondents.

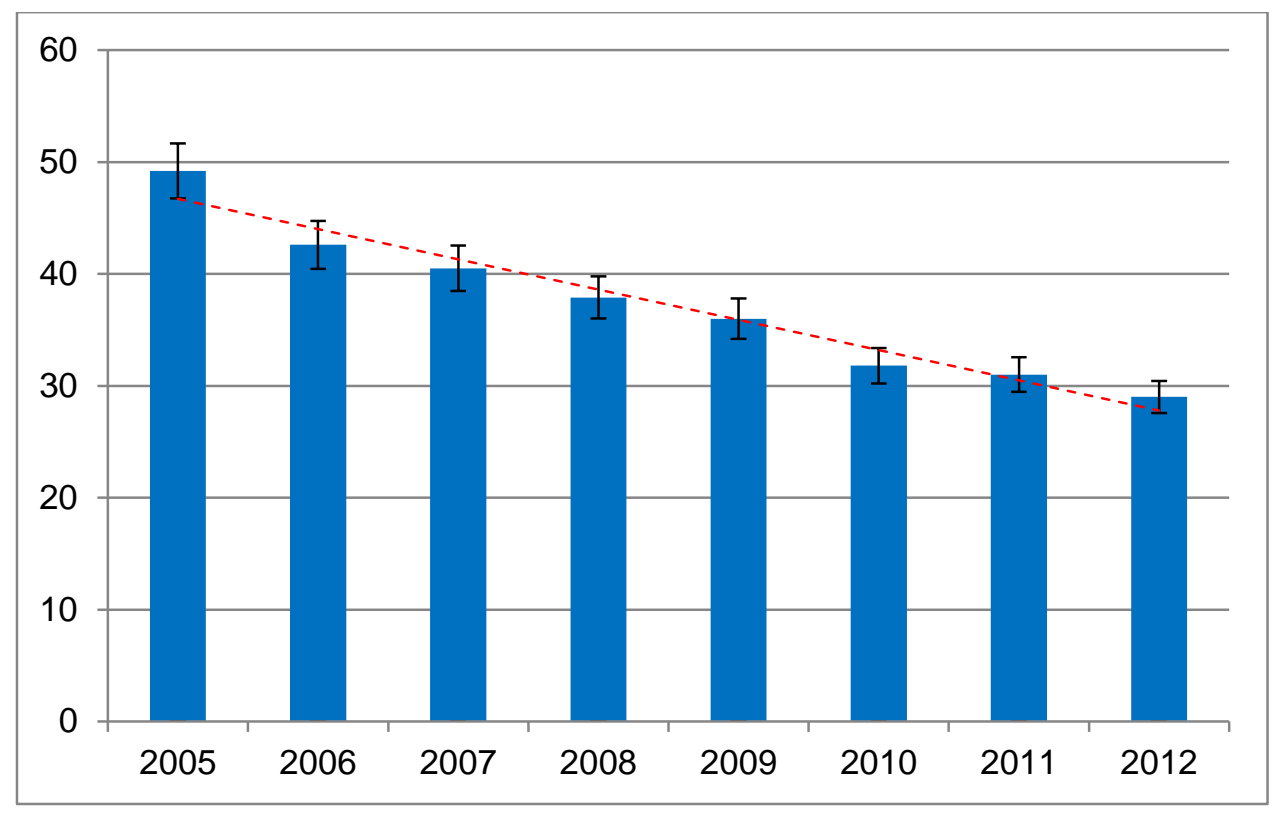

Figure 16: Quality of Life Measure on ASB

On the other hand, in the most recent British Crime Survey interviews (year ending March 2013) $52.7 \%$ of respondents 'agreed' or 'strongly agreed' that: 'The police and local council are dealing with the anti-social behaviour and crime issues that matter in this area', a 2.9\% reduction from the same period in 2009. In addition, at least seven out of ten service users felt satisfied with the overall services provided by the Police for ASB incidents (77.2\%).

User satisfaction regarding follow up service by the Police for ASB has improved slightly at $63.6 \%$, whilst satisfaction with overall service $(77.2 \%$ ) declined significantly in 2012/2013. Nevertheless, both measures are meeting the Police Authority target for the year. Looking into the equality strands of the service users, younger respondents (aged 16 24 years) were more satisfied with the quality of services provided by the Police with regard to ASB compared to other age groups ( $10.7 \%$ difference).

Victim

- Vulnerable Victims

Since May 2011, Avon and Somerset Police have been using a new ASB call handling process called ProQA, the only force in England and Wales to do so. ProQA aims to identify the nature of the reported incident quickly and effectively ensuring the most appropriate outcome for the victim. The Police also undertake risk assessment and aggregate the victims for suitable treatment. As soon as the victim is highlighted as vulnerable, ProQA prioritises the call as 'immediate' or 'priority' for response. In 2012/2013, 1529 (21\%) incidents were classified as requiring immediate response, whilst another 3,506 (48\%) incidents were classified as requiring priority response from the Police.

Landlord Services of Bristol City Council also conducted risk assessments on 1,649 victims. This assessment considers the history of the incidents, the victims' vulnerability towards hate crime and the support they need. 


\section{- Victim Contact}

The Council's Landlord Services has implemented a service improvement plan that focuses on case acknowledgements and action plans. In the last financial year, $97 \%$ of the ASB cases were actioned and supported with action plans within 10 working days. $90 \%$ of the closed cases were successfully resolved, with an average case duration of 83 days. $86 \%$ of the service users satisfied with the service provided and $84 \%$ of the users satisfied with the outcome of their cases.

In 2012/2013, the overall victim satisfaction with regard to the treatment that they received from the Police was $77.6 \%$. This means that almost eight out of ten Bristol citizens who had contacted the Police last year regarding anti-social behaviour were satisfied with the Police treatment. In addition, there is no significant variation in terms of the demographics of these groups of these people (age, gender, ethnicity and disability). The revised target in 2013/2014 is $82.8 \%$, with a stretched target of $86.7 \%$ in $2016 / 2017$.

The victims also mentioned that they would like the Police to do follow-up contacts after they have been in touch with the Police and fulfil their promises, which are considered to be opportunities to increase the satisfaction level. Responding to these needs, the Police have implemented call backs for all ASB calls as part of their ASB Gold Standard. The call back rate has increased significantly since it started and most areas are now meeting the $90 \%$ call back target.

HouseMark's anti-social behaviour benchmarking system was developed by the Institute of Housing, to help social landlords measure and understand the anti-social incidents they are tackling on a day-to-day basis. Using the tool to benchmark the Council's performance against the national performance, Landlord Services managed 86

anti-social behaviour cases per thousand properties in 2012/2013, compared to 70 ASB cases nationally. This indicates a higher level of need of Council tenants with regard to managing the incidents in Bristol. Most of the incidents were tackled through early intervention actions, illustrated by Figure 17 below:

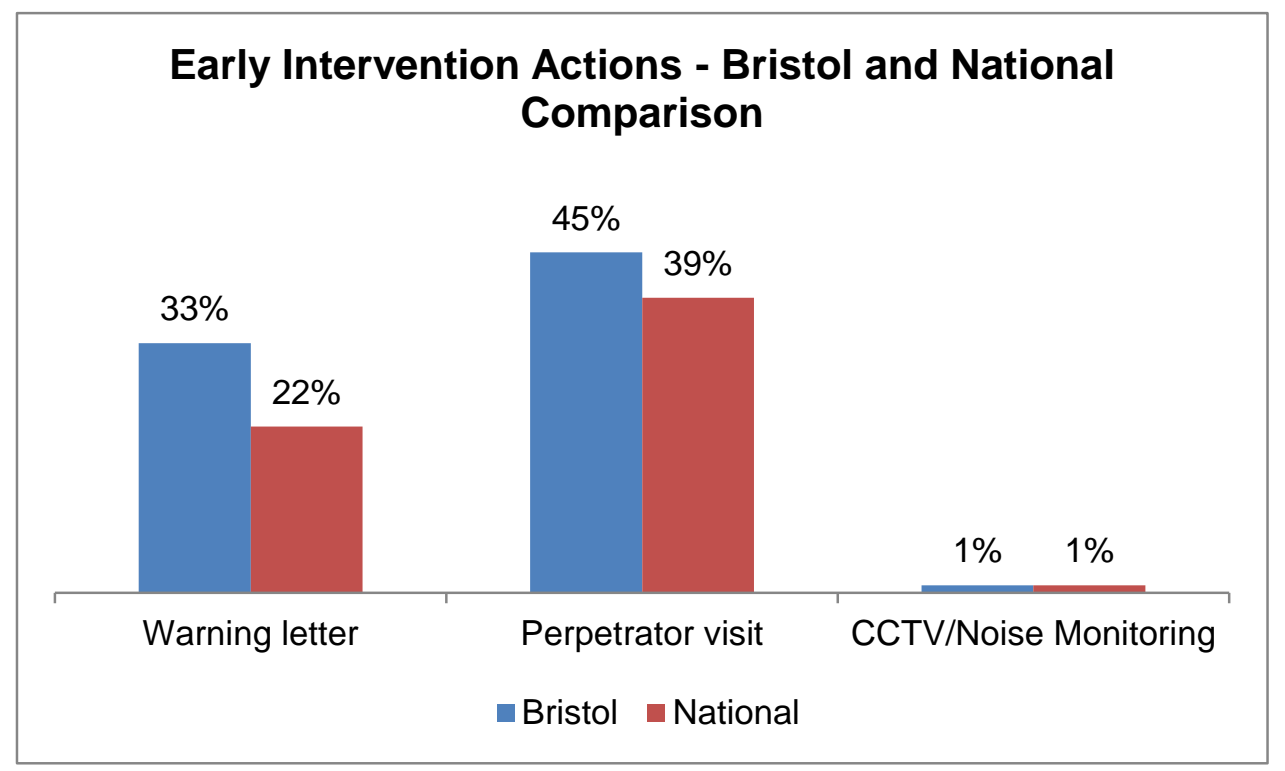

Figure 17: Early Intervention Actions - Bristol and National Comparison

\section{Offender}

Dealing with the offenders of anti-social behaviour offences in Bristol, the Police imposed the following sanctions in 2012/2013:

- $\quad$ Letters to the offenders - 799

- Acceptable Behaviour Contracts (excluding those under sexual offences) -118

- Anti-social Behaviour Orders (including post convictions and injunctions) - 87

- $\quad$ Crack house closures - 8 


\section{- Repeat Offenders}

Repeat offenders are monitored with an incremental partnership approach to tackling their behaviour. In $2012 / 2013$, there was a $28 \%$ decrease in the number of active Anti-social Behaviour Orders pertaining to council tenants (445 orders). The number of injunctions in force by the end of the financial period, and tenancy actions were more or less the same (+/-2), with more Notice of Possession Proceedings being served and outright possession orders undertaken by the Council recorded. Two undertakings were also obtained.

The ASB indicator of the Council ${ }^{47}$ shows that there was a reduction in the number of high street impact drinkers up to 25 offenders. In addition, the reduction in the impact of street drinking in Bristol can also be seen under the Quality of Life survey (50.3\%).

To tackle repeat offenders of ASB, one of the initiatives currently being undertaken is through the Troubled Families agenda. The Troubled Families agenda is a national programme that requires the local authorities across England to identify families with the following characteristics:

- No parent in the family is in work;

- Family lives in overcrowded housing;

- No parent has any qualifications;

- Mother has mental health problems;

- At least one parent has a long-standing limiting illness, disability or infirmity;

- Family has low income (below $60 \%$ of median income);

- Family cannot afford a number of food and clothing items.

Unless helped, these problems can prevent a family from moving forward, and drain public purse by £9 billion per annum.

In Bristol, there are 1,355 families that have been identified as part of the Troubled Families Scheme for the next three years. A team of 27 key workers, 11 specialists and three supervisors is currently working closely with 697 families. So far, the team has claimed 82 successes under the Government's Payment by Result Scheme, and will be expected to claim 300 additional successes. The team works closely with the Police, health services, job centres, and schools to create tailor made interventions for the whole family.

The programme has recently been extended by five years, and so has now become an eight-year programme. Due to this extension, it is likely that the team will be working with up to 4,400 families. This also means that the team will have more resources and capacity to tackle the troubled families in Bristol. The criteria will be developed and it is expected that adult crime, looked after children, and earlier support for troubled families will be included in the new criteria but this has not yet been announced.

Within the Troubled Families Scheme, there are Family Intervention Teams. These went live in March 2013, operating on an area basis of North, South, and East Central Bristol, to take a holistic in whole family approach to managing repeat offenders and perpetrators of anti-social behaviour. The troubled families are being addressed through the new Early Intervention Service (EIS) to cover the anti-social behaviour incidents, resulting from changes across CYPS on prevention activities.

The Neighbourhood Justice Project went live in May 2012, addressing low level crime and anti-social behaviour using a restorative approach. The project is currently made up of a trainer and 18 volunteers. To date 112 referrals have been made to the project, with 41 progressing to a restorative conference. Of those 41 cases, 40 have achieved successful outcomes. To compliment this pre-sentencing service, Avon and Somerset Police provide a restorative based programme for post sentencing IMPACT cases, with a dedicated officer facilitating restorative conferences in Bristol prisons.

The Streetwise Project is a part of Bristol City Council's ASB Team. It was set up 11 years ago to tackle "streetbased" anti-social behaviour, such as begging, street drinking and rough sleeping. The underlying causes of the clients' behaviour are examined and attempts are made to address these causes through offering supportive interventions on the proviso that they agree not to cause further issues. This agreement is made through informal enforcement tools such as Acceptable Behaviour Contracts. Where supportive interventions and informal

${ }^{47}$ ASB Indicator is a local performance metric which combines the casework, output and perception of residents based on the Quality of Life survey, monitored by the ASB Delivery Group. 
enforcement does not succeed in stopping the behaviour (or at least drastically reducing it) formal enforcement (typically ASBO and Injunction) follows.

It is estimated through the Streetwise Project that in Bristol, there are:

- Street drinkers -200 people

- Beggars - 100 people

- Rough sleepers - 90 people

There may be an overlap between the above mentioned groupings.

In the current Streetwise cohort (66 offenders), an average of 14 are determined as being particularly high-risk (either to themselves or to others). A large proportion of these clients are from ages $40-49(27,41 \%)$ and $30-39(24$, $36 \%)$. The majority of them are male $(58,88 \%)$. The project currently does not collect the data on the ethnicity of these offenders.

Most of the conditions of the orders issued prevented the offenders from entering Bristol City Centre (8, 42\%), and also from the following places: Bedminster, Filwood, Kingsdown, Knowle, Clifton, Southville and Easton.

\section{Location}

There was an increase in the number of ASB Orders covering the wards of Cabot $(+25 \%)$ and Lawrence Hill (4\%). The majority of clients with these orders declared to have no fixed abode. In addition, injunctions against those offenders with no fixed abode also increased by $40 \%$ (75).

\section{Recommendations}

- Map the locations of ASB incidents against the Troubled Families in Bristol to see whether there is any correlation between these two strands.

- Consider increasing the use of conflict resolution for minor ASB cases, including mediation and restorative justice.

- Continue to target individuals involved in street-based ASB, including persons of no fixed abode, through coordinated offender management.

- Consider looking into prolific offenders and vulnerable victims profiles, and cohort of offenders with complex needs such as mental health.

- Produce the profile of the vulnerable victims within Bristol in the forthcoming ASB Needs Assessment.

- Develop anti-social behaviour performance measures with other core cities, as there is no performance comparison available between Bristol and core cities.

- Focusing resources through Fulfilling Lives ${ }^{48}$ on street ASB clients and consider extending the focus on pathways out.

${ }^{48} \mathrm{~A}$ scheme that supports people with multiple and complex needs. 


\section{Hate Crime}

\section{Overview}

The Home Office defines 'hate crime' as 'any incident, which constitutes a criminal offence that is perceived by the victim or any other person as being motivated by prejudice or hate'. This definition covers five main strands: disability, gender-identity, race, religion or faith and sexual orientation. However, Safer Bristol has adopted a broader definition that also captures hate 'incidents' - incidents that may not constitute a criminal offence but are still perceived by the victim as being motivated by prejudice or hate.

In recent years, Bristol has undergone a major demographic change, more so than any other city in Britain, making it one of the most diverse cities outside of London. Between Census 2001 and Census 2011, there had been an increase in the number of people from black and minority ethnic communities in Bristol $(+7.8 \%)$, along with an increase in the number of people who were born outside of the UK $(+6.5 \%)$, and an increase in people of all other religions except Christian. $12.4 \%$ of people of working age are disabled which rises to $16.7 \%$ of the population as a whole.

The 2011 Census did not record sexual preference. However, there is a local agreement to estimate the number of lesbian, gay or bisexual in Bristol, which is between five and seven percent of the total population. Whilst many people enjoy living in a diverse city, the city does recognise that there are a number of community tensions which need to be managed to mitigate escalation. Managing hate crime is an essential part of maintaining safety in the city.

Hate crime responses in Bristol are governed through the multi-agency partnership known as Strategic Partnership against Hate Crime (SPAHC). Avon and Somerset Police chair this group, and the membership includes Bristol City Council (Safer Bristol, Landlord Services, Children and Young People Services), provider representation, and Victim Support.

Partnership activities that are delivered to help support victims of hate crime and improve community confidence include the city's Tension Monitoring Group. Hate Crime Case Review Panels and voluntary sector providers, delivering hate crime community-based support services to address race hate, disablist, homophobic, age and gender incidents and crimes.

Safer Bristol has recently awarded grant funding to SARI, Brandon Trust, Bristol Mind and Bristol LGBT to work in collaboration to deliver a hate crime support services across Bristol. The service commenced on 3rd June 2013.

Key elements of service delivery include:

- Risk assessments of referrals

- Case management service which is victim centred

- Practical support including additional security, support to take action against the perpetrator and confidence building

- Offer one-off advice or signposting

- Provide out of hours response for victims

- Deliver awareness/ empowerment sessions and cohesion projects in schools and communities

- Develop a Service User Strategic Group (SUSG) to influence responses to hate crime

An official launch of the new service took place in September 2013.

\section{Performance}

There were 1,584 incidents reported in 2012/2013, where 1,261 incidents were related to race hate, followed by disablist (176 incidents), homophobic (110 incidents), transphobic (five incidents) and religion (32 incidents).

Figure 18 below shows the overall hate crime trend in 2012/2013, by quarter and by partner agencies, whilst Figure 19 shows the number of hate crime incidents by strands. Race hate incidents account for the largest number of incidents, followed by disablist and homophobic (note that there might be potential overlap in terms of the number of clients seen by the agencies). 


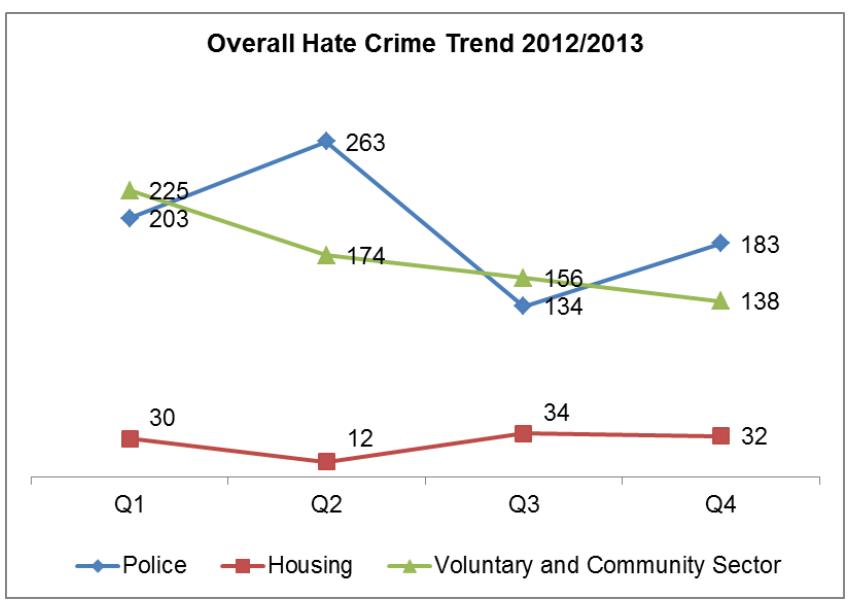

Figure 18: Overall Hate Crime Trend 2012/2013

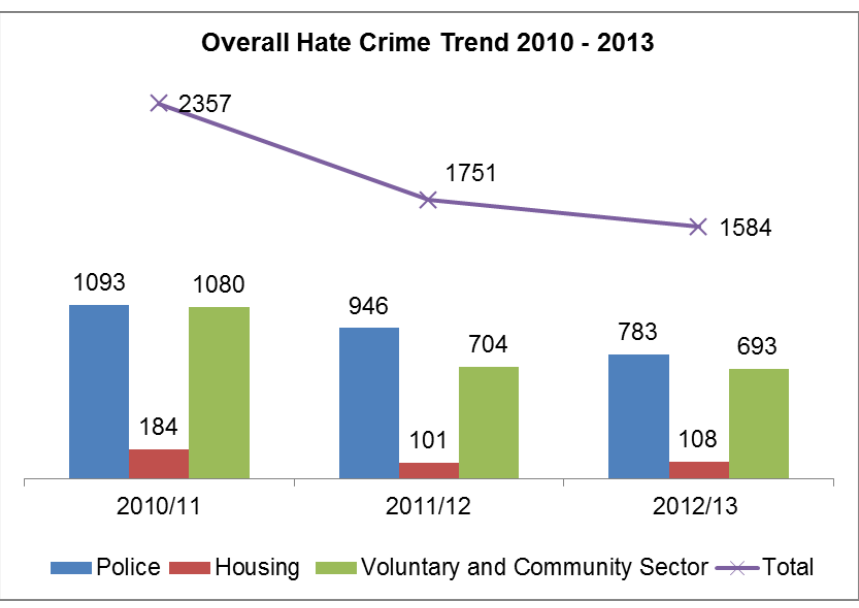

Figure 19: Overall Hate Crime Trend 2010 - 2013

There were 783 hate crime incidents reported to the Police in Bristol in 2012/2013, a $7 \%$ decrease compared to $2011 / 2012$ (837), which suggests that hate crime is still significantly underreported. $54 \%$ of hate crimes reported to Avon and Somerset Police occurred in Bristol. Nevertheless, the number of hate crime incidents reported to the Police shows that two incidents happen on a daily basis. It is anticipated that the Service User Strategic Group can offer valuable insights into why reporting to the Police has declined so significantly and what can be done to increase reporting.

The number of incidents reported to the support agencies decreased by $2 \%$. In 2012/2013 (693 incidents as opposed to 704 incidents the year before). In addition, there were 108 incidents reported to the Council's Landlord Services during the same period of time, by council tenants. This represents a $6 \%$ increase in the number of incidents reported to the Council compared to $2011 / 2012$.

Among the core cities in England, Bristol has the second highest rate reported crime for racially/religiously aggravated offences per thousand population in 2012/2013, illustrated by Table 11 below:

\begin{tabular}{lc}
\hline Core City & Rate Per Thousand Population \\
\hline Sheffield & 0.30 \\
Newcastle & 0.54 \\
Leeds & 0.72 \\
Nottingham & 0.79 \\
Birmingham & 1.04 \\
Liverpool & 1.11 \\
Bristol & 1.16 \\
Manchester & 1.31 \\
\hline
\end{tabular}

\section{Table 11: Core Cities Comparison of Hate Crime Incidents}

Schools no longer submit data into a central source, therefore whilst most schools do record and deal with incidents it is unclear to what extent hate crime is prevalent within children and young people. The Pupil Voices Survey ${ }^{49}$ found that $22 \%$ of secondary pupils, $29 \%$ of male primary school pupils and $44 \%$ of female primary school pupils were afraid of going to school because of bullying at least sometimes, some of these concerns may relate to bullying which is 'hate motivated'.

The Quality of Life Survey 2012 shows a positive trend for community cohesion indicators, with an increasing percentage of respondents who agree that people treat each other with respect in their area, along with those who agree that people from different backgrounds get on well together and ethnic differences are respected in their neighbourhood: 


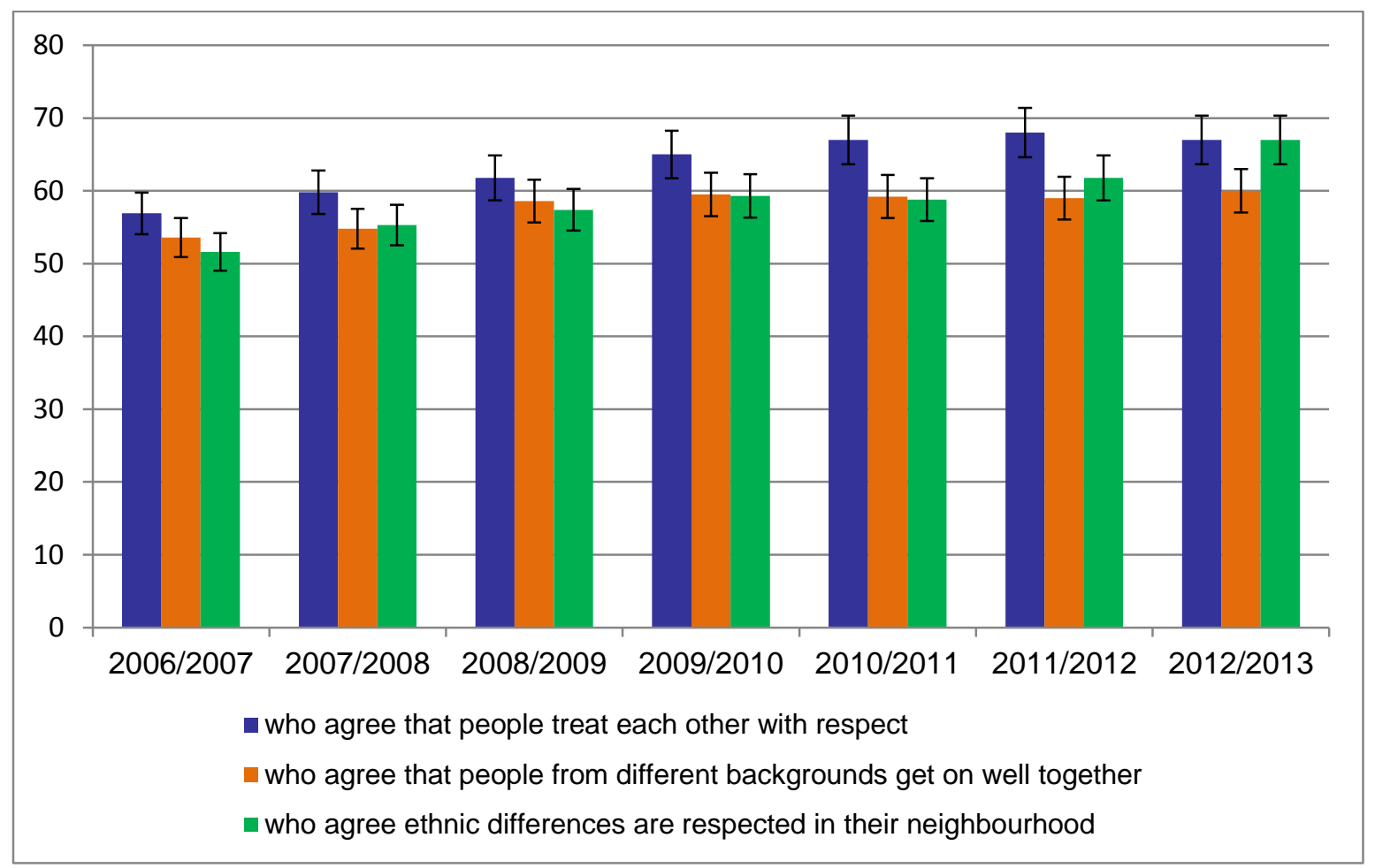

Figure 20: Quality of Life Survey Results on Community Cohesion in Bristo/50

\section{- Under-reporting}

The Government's Hate Crime Action Plan 2012 identified a number of reasons for under-reporting, and these issues are familiar to people working with hate crime victims in Bristol:

- Incidents happen too often to report each one

- Victims doubt whether the abuse or attack is serious enough to bother reporting it, or do not know whether it qualifies as a crime offence

- Fear of being further victimised

- Concern that the Police will not be able to do anything

- Concern that the organisations will not do anything because they are prejudiced and/or unsympathetic

- Victims fear that they will be 'outed', for example as being gay or having mental health needs. Lack of access makes reporting too difficult, for example, interpreters are not available or a person using a wheelchair does not have adequate access to premises. ${ }^{51}$

SPAHC has developed the Hate Crime Strategy 2010-2014. One of its high priority strategic aims is to increase victim confidence in reporting and signposting the various support agencies and third party reporting centres that exist in Bristol.

In line with the concerted efforts to improve hate crime reporting, Safer Bristol has commissioned a web-based case management system (called Theseus) to capture incident reports and the activity of the hate crime support service. The intention is for Theseus to be used by the Police and Landlord Services to facilitate seamless data sharing and to provide improved intelligence in relation to hate crime incidents in Bristol. It is anticipated that the reporting of the incidents will commence from November 2013 onwards.

It is recognised that hate crime incidents are under reported. Across the Avon \& Somerset area, reported racially and religiously aggravated offences $(+4.1 \%)$ and race/faith-flagged incidents $(+2.4 \%)$ are now increasing, potentially reflecting improvements in confidence to report such incidents. ${ }^{52}$ SPAHC which monitors reports of incidents to the

\footnotetext{
50 Confidence intervals are included in the chart, in the form of error bars, as the Quality of Life Survey is based on a sample of population rather than a census.

51 HM Government, 'Challenge It, Report It, Stop It: The Government's Plan to Tackle Hate Crime' (2012), available at: https://www.gov.uk/government/uploads/system/uploads/attachment data/file/97849/action-plan.pdf (accessed: 29 $9^{\text {th }}$ July 2013)

${ }^{52}$ Avon and Somerset Police and Crime Needs Assessment (Working Document, October, 2013).
} 
Avon \& Somerset Police, Bristol City Council's Landlord Services and the hate crime support services has noted a decrease in reports in Bristol.

Victim

The majority of the victims reporting incidents to the Police are aged $35-44$ years and male, based on Tables 12 and 13 below:

\begin{tabular}{lc}
\hline Age Band & Number of Victims \\
\hline Under 16 & 25 \\
$17-25$ & 112 \\
$26-34$ & 172 \\
$35-44$ & 204 \\
$45-54$ & 129 \\
$55-64$ & 46 \\
65 and above & 17 \\
Not recorded & 84 \\
\hline
\end{tabular}

Table 12: Age of hate crime victims

\begin{tabular}{lc}
\hline Gender & Number of victims \\
\hline Female & 266 \\
Male & 481 \\
Not recorded & 58 \\
\hline
\end{tabular}

Table 13: Gender of hate crime victims

In addition, 130 victims (16\%) had been a victim of hate crime in the past, and 150 victims (19\%) had been a victim of other crimes in the past. In this context, it can be concluded that almost two out of ten hate crime victims were a previous victim of hate crime and/or other types of crime, indicating the vulnerability of these victims.

SPAHC is developing a risk matrix and case management system to manage high risk cases and reduce repeat incidents.

The victims' satisfaction with their experiences in dealing with the Police when reporting the incidents remains high $(80 \%){ }^{53}$

\section{Offender}

SPAHC strategic objectives include promoting zero tolerance of hate crime and increasing the rate at which offenders are brought to justice. Therefore, it is positive to note that the detection rate for hate crime in $2012 / 2013$ is $36.5 \%$, a significant increase from only $27 \%$ in $2011 / 12$. Of those detected, $80 \%$ of the offenders were charged, whilst another $8 \%$ were cautioned and $12 \%$ undertook restorative justice routes. In 2013 , the use of restorative approaches in hate crime incidents is being developed in a specific project for younger perpetrators. Restorative approaches have also been used for incidents where formal charges have not been brought.

Within Bristol, there were 391 perpetrators of hate crime identified in 2012/2013. Figure 21 below shows the number of perpetrators by incident number, where the vast majority of offenders are only linked to one offence, with $16 \%$ of offenders identified as repeat offenders:

${ }^{53}$ Note that this only relates to race hate as per the Home Office Guidelines in monitoring victims' experience and satisfaction. 


\section{Number of Perpetrators, by Incident}



Figure 21: Number of Perpetrators by Incident

The majority of the hate crime offenders are male $(190,77 \%)$ and White European $(157,34 \%) .{ }^{54}$ The table below shows a breakdown of age for the hate crime offenders as recorded by the Police.

\begin{tabular}{lccc}
\hline Age Group & Number & $\%$ & \% of Population in Bristol \\
\hline 17 and under & 39 & 10 & $20 \%$ \\
$18-25$ & 88 & 23 & $15 \%$ \\
$26-34$ & 87 & 22 & $16 \%$ \\
$35-49$ & 106 & 27 & $20 \%$ \\
$50-64$ & 35 & 9 & $15 \%$ \\
65 and above & 6 & 2 & $13 \%$ \\
Not recorded & 30 & 8 & $100 \%$ \\
Total & 391 & $100 \%$ & \\
\hline
\end{tabular}

\section{Table 14: Age of hate crime offenders}

Although the largest group of offenders is $35-49$ years, it is noted that $35 \%$ of the perpetrators are young people aged 25 years and below. This also means that the tendency of young people from this age group to become hate crime perpetrators is 1.7 times higher than other age groups.

In terms of the location of these offenders in Bristol, the highest number of offenders came from Lawrence Hill ward $(42,11 \%)$. It is also noted that 96 perpetrators came from the neighbouring areas, or were not recorded:

- South Gloucestershire - 30

- $\quad$ Bath \& North East Somerset - 6

- North Somerset - 8

- $\quad$ Not recorded -52

According to a recent study by the Equality and Human Rights Commission, the profile of hate crime offenders tends to be male, from white backgrounds and unemployed. ${ }^{55}$ Modelling these findings into the local areas, the areas that have a high propensity of male, white backgrounds and unemployed are Lockleaze, Ashley, Easton, and Lawrence Hill. ${ }^{56}$ Based on the Police data, Lawrence Hill and Ashley wards are in the top five locations where the offenders came from.

It is also noted that these findings correspond with the areas that have a high number of Council properties. Lawrence Hill and Lockleaze are among the areas that have a high number of Council properties.

\footnotetext{
${ }^{54}$ Based on ethnic appearance recorded by the Police officers.

${ }^{55}$ Rehabilitation of Hate Crime Offenders' (2011), available at:

http://www.niacro.co.uk/filestore/documents/Rehabilitation\%20of\%20Hate\%20Crime\%20Offenders-

Equality\%20\&\%20Human\%20Rights\%20Commission\%20Scotland-Spring\%202011.pdf (last accessed: 29 ${ }^{\text {th }}$ July 2013)

56 Bristol City Council, 'Neighbourhood Partnership Statistical Profiles', available at: http://www.bristol.gov.uk/page/council-anddemocracy/neighbourhood-partnership-statistical-profiles (last accessed: $29^{\text {th }}$ July 2013).
} 


\section{Location}

The table below shows the number of hate crime cases recorded by the Police, by the Neighbourhood Delivery Team (NDT) area in Bristol. It is noted that Trinity, Brislington and Cabot and Clifton are the top three NDTs that recorded hate crime cases in 2012/2013 and quarter 1 2013/2014.

\begin{tabular}{lccccc}
\hline NDT Area & $\mathbf{2 0 1 2 / 1 3 ~ Q 1 ~}$ & $\mathbf{2 0 1 2 / 1 3 ~ Q 2 ~}$ & $\mathbf{2 0 1 2 / 1 3 ~ Q 3 ~}$ & $\mathbf{2 0 1 2 / 1 3 ~ Q 4 ~}$ & 2013/14 Q1 \\
\hline Bishopsworth & 23 & 16 & 13 & 12 & 21 \\
Brislington & 18 & 28 & 20 & 22 & 30 \\
Bristol East & 26 & 19 & 15 & 21 & 28 \\
$\begin{array}{l}\text { Cabot and } \\
\text { Clifton }\end{array}$ & 42 & 30 & 34 & 33 & 33 \\
$\begin{array}{l}\text { Redland and } \\
\text { Lockleaze }\end{array}$ & 15 & 10 & 10 & 9 & 13 \\
$\begin{array}{l}\text { Southmead and } \\
\text { Avonmouth }\end{array}$ & 29 & 15 & 18 & 12 & 19 \\
$\begin{array}{l}\text { Trinity } \\
\text { Missing post }\end{array}$ & 39 & 27 & 24 & 40 & 42 \\
codes & 11 & 118 & 0 & 34 & 6 \\
Total & & & & & 183 \\
\hline
\end{tabular}

\section{Table 15: Hate Crime by NDT Areas}

The Quality of Life Survey 2012 highlighted that the wards in the Dundry View areas were below the city average of $60 \%$ of residents agreeing with the statement that people from different backgrounds get on well together. In particular, Bishopsworth is the lowest in the city. Following anecdotal evidence that community tensions were escalating and hate crime was unreported, in 2013, Bristol City Council commissioned a study on hate crime incidents in the Dundry View Neighbourhood Partnership area. The area consists of the three wards of Whitchurch Park, Hartcliffe and Bishopsworth.

The study noted that although race hate crime incidents are relatively low in absolute numbers compared with some other areas of Bristol, residents from ethnic minority backgrounds are more likely to be a victim of hate crime in the Dundry View area than in the rest of Bristol. There is significant under-reporting of hate crime incidents, especially disablist crimes and incidents. The report noted 'mate crime' (where 'mates' befriend disabled people who are vulnerable specifically for the purpose of exploiting and abusing the disabled person) is seen as a particularly complex issue to effectively address. There was limited evidence of homophobic hate crime. An action plan will be developed and lessons relevant to other areas of the city will be implemented.

Since the 2001 Census the city's total percentage for residents from BME groups has grown from $8.2 \%$ to $16.0 \%$, yet the totals in the Dundry View wards has only increased from $2.8 \%$ to $4.3 \%$. Similarly the percentage of residents from other white groups, mainly from Eastern Europe, has only increased from $0.8 \%$ to $1.6 \%$ compared with an increase across the city from $2.7 \%$ in 2001 to $5.1 \%$ in 2011 .

Whitchurch Park, Bishopsworth, and Hartcliffe have three of the top four highest rates of hate crime $(175 / 1,000$ population, 140/1,000 population, and 118/1,000 population respectively) in the city, compared with wards with higher numbers of BME residents - Easton and Old Market (Lawrence Hill ward) has only 16/1,000 and St Pauls (Ashley Ward) only $5 / 1,000.57$

\section{- Community Cohesion}

The Tension Monitoring Group (TMG) is a multi-agency operational group that meets monthly and includes the Council, Police and voluntary sector, of which Safer Bristol is the lead partner. The group produces monthly briefing updates on community impactive tensions. All partners are signed up to ensure that policy initiatives are being merged with community development and community cohesion work. Work is continually undertaken to ensure that there is an understanding of the demographic changes within the city and that these are being managed.

${ }^{57}$ Bristol Hate Crime Needs Assessment 2010/2011 (2011). 
The group discusses tension levels in every area of Bristol, looking at issues and identifying actions to mitigate. The group assesses the level of tension by looking into the following factors:

- Immediacy of event (how soon might something happen)

- Seriousness of event (nature of the incident or threat)

- Magnitude of event (number of people who could be affected)

- Media profile (level/tone of reporting)

- Previous experience or history

Within the city, the TMG has looked at a spate of tyre slashing in Filwood, incidents and issues on Stapleton Road, as well as other community tensions that have led to hate crime incidents after a major event such as the Woolwich murder. The group discussed and action planned preventative work with partners and local communities to reduce any tensions that the English Defence League (EDL) march in Bristol and possible tensions that might have arisen, as it was held on the same day as Bristol Pride and an Anti-Fascist march.

\section{Recommendations}

- The focus on increasing the number of reported hate crime incidents remains important. The organisations should consider increasing opportunities for victims to come forward to report incidents and instil confidence in reporting to the organisations themselves.

- Increase the use of the restorative justice approach on minor incidents.

- Consider producing a prevalence report on hate crime incidents, to determine the gap between the number of current incidents and the number of incidents that should have been reported through appropriate channels.

- Consider an analysis on factors that increase likelihood of certain characteristics that may be target of hate crime, such as ward, ethnicity, disability etc.

- Ensure new hate crime case management system is used by all statutory organisations for reporting incidents.

- Further exploration of profile of offenders to see how we can target potential offenders.

- Define through SPAHC how a repeat victim is defined and ensure this is used as part of monitoring performance.

- Adopt a multi-agency approach to risk assessment to effectively manage high risk cases.

- Review the effectiveness of restorative justice in this area and build on the successes.

- Increase preventative activities and promote third party reporting to increase community confidence in Dundry View. 


\section{Prevent}

\section{Overview}

Prevent is one of the four strands of CONTEST, the UK strategy for countering terrorism. It is aimed to work closely with individuals who are likely to adopt extremist views, and work in partnership with other agencies and our communities to identify individuals who may need our support.

The government has developed a training session called 'WRAP' (Workshop to Raise Awareness of Prevent) for frontline public sector staff to explain how people become radicalised and what to look out for, as part of the Prevent agenda. Training sessions have been held throughout the year for Bristol City Council staff. To date, there are over 250 staff who have been trained under this programme, and additional training has been undertaken with individual teams.

A process called 'Channel' has been developed to support people at risk of being drawn towards terrorism and violent extremism. Bristol City Council, Avon \& Somerset Police and other partners, including Probation, health agencies, community organisations and individuals within local communities work together to support vulnerable individuals who are prone to radicalisation and revised tailored safeguarding measures to support their needs are taken.

A range of options is available including mentoring, welfare support and access to key services. These services often prevent people from becoming involved in crime.

Since April 2012, there were three referrals made to the Channel, mainly for the reason of preaching or expression of views. There were also 15 cases of engagement work and 22 intelligence activities took place during the same period of time.

\section{Recommendations}

- Improve the data collection on the potential victims, offenders and locations to understand opportunities and threats under this crime.

- Consider the use of community mediators for the low level issues to diffuse the situation from escalating further.

- Mainstream the Prevent strategy through safeguarding adults and safeguarding children policy to ensure that vulnerable people are adequately protected.

- Ensure that the Prevent strategy is linked to other areas of crime prevention strategies such as hate crime. 


\section{Reducing Re-offending}

Avon \& Somerset Probation Trust (ASPT) aims to contribute to a fair and effective criminal justice system which will provide justice for victims and local communities, punishment and reform for offenders and value for the taxpayer.

Probation manages offenders as part of their sentence from the courts, delivers interventions (for example, delivery of programmes, community payback and the running of Approved Premises) and produce case studies supporting the level of sentences. Further to the recent inspection of the ASPT, the Trust is rated 'good' by National Offender Management Service.

\section{Adult Offenders}

\section{Performance}

In 2012/2013, the rolling annual cohort size of local adults re-offending in Bristol is 7,644 clients. The actual rate of binary re-offending in any three month period by this cohort is $10.8 \%$, which represents a nominal variation compared to the predicted rate of re-offending, which is $10.6 \% .{ }^{58} 408$ of these clients were classified as posing a high or very high risk of harm to the public. 28 of these clients re-offended $-6.9 \%$ compared with a predicted rate of $9.5 \%$. The vast majority of these re-offences were of a non-severe nature according to Ministry of Justice guidelines.

200 offenders were responsible for $60 \%$ of all re-offences in 2012/13. In contrast, 893 clients were not convicted or cautioned of any re-offence at all.

\section{Re-offending by Crime Type}

The problem of re-offending is particularly related to shoplifting offences. $32 \%$ of offenders who are shoplifters will go onto re-offend in any 3 month period. Almost a quarter of all offenders who go onto reoffend are convicted or cautioned of shoplifting as their first re-offence. For women offenders this figure rises to almost a half.

Apart from shoplifting, the re-offending rates are high for those clients initially convicted of other types of acquisitive crime, such as burglary (18\% go on to reoffend) and theft other (13\%). Re-offending rates for criminal damage/public order and common assault are $12 \%$ and $10 \%$ respectively. These types of clients have high levels of need around alcohol and drug misuse, accommodation and employment.

It is important to note for clients initially convicted of more serious violent and sexual offences re-offending rates are lower $(7 \%$ and $2 \%$ respectively). The actual types of re-offence are less serious than the initial offence. This is in line with the Ministry of Justice research which indicates that around $58 \%$ of adult offenders convicted of a theft offence go on to re-commit a similar offence within 12 months. $559(70 \%)$ of the most high risk offenders had their needs assessed prior to their offences. The court is able to impose Drug Rehabilitation Requirement (DRR). $34 \%$ of DRR clients had an index offence of shoplifting.

\section{Core Cities Comparison}

In terms of binary re-offending, Bristol is not performing as well as the other seven core cities in England who are all improving rapidly. However, in terms of the number of re-offences (also known as frequency of re-offence), Bristol is a joint first with Manchester, as per Table 16 below:

\begin{tabular}{lccc}
\hline \multicolumn{1}{c}{$\%$} & $\mathbf{2 0 0 8 / 2 0 0 9}$ & $\mathbf{2 0 1 2 / 2 0 1 3}$ & $\begin{array}{c}\text { \% Rate of Change in Re-offending } \\
\text { Between 2008/2009 and 2012/2013 }\end{array}$ \\
\hline Manchester & 20 & 16 & $-4 \%$ \\
Bristol & 24 & 20 & $-4 \%$ \\
Birmingham & 15 & 12 & $-3 \%$ \\
Liverpool & 17 & 14 & $-3 \%$ \\
Nottingham & 20 & 17 & $-3 \%$ \\
Sheffield & 19 & 17 & $-2 \%$ \\
Leeds & 20 & 18 & $-2 \%$ \\
Newcastle & 36 & 34 & $-2 \%$ \\
\hline
\end{tabular}

Table 16: Rate of Change in Re-offending by Core Cities

${ }^{58}$ Ministry of Justice, 'Local Offending Statistics' (2013). 
In Bristol, the offender management approach has successfully targeted the most prolific offenders in reducing the frequency of re-offences in a way other cities may not have seen but equally the approach may give less support to the binary method of counting re-offending.

\section{Activities}

The following activities were undertaken in 2012/2013. Some of them are currently being continued in the current fiscal year:

- Door Workshop was undertaken by looking at the delivery of services to prisoners sentenced to short-term custody with statutory and voluntary sector partners. Following the workshop, Probation expanded the use of peer mentoring schemes and meeting released prisoners at the prison gate.

- Launched an IMPACT Pathways website to collate and disseminate information about the availability of pathway support to support rehabilitation and how to access that support.

- Carried out research into the causes and extent of shoplifting with the University of the West of England (UWE) Bristol.

- Continuing the availability of restorative justice approaches that lead to face-to-face victim and offender conferencing, particularly for victims of acquisitive crimes committed by offenders managed by IMPACT.

\section{Recommendations}

- Increase the use of voluntary electronic tagging for prolific offenders

- Design specific interventions for prolific shoplifters to reduce re-offending

- Work with Eden House, which is the women-only offenders housing support, to provide specialist provisions for those who are known as prolific shoplifters

- Provide Peer Mentoring Service for the most vulnerable offenders

- Work closely with the families of offenders to support them to help reduce risk of further offending

- Continue to expand the availability of restorative justice within the local criminal justice system, both pre and post-sentence, to ensure that victims of crimes are at the heart of restorative justice

- Focus on using IOM teams for those service users who pose the highest risk of re-offending and serious harm to our communities.

- Work with the voluntary sector organisations to provide a greater provision in the community, specifically working with offenders under supervision and who have been released from prison into the community.

\section{Youth Offenders}

\section{Performance}

The Youth Justice System comprises statutory agencies such as Avon \& Somerset Police, Children's Services, Education and Health, and voluntary and community organisations. These organisations form the multi-agency Youth Offending Team (YOT) Board Partnership which governs the system and oversees the delivery of activities by Bristol YOT.

The performance of the youth justice system is monitored through three key result areas, namely numbers of first time entrants into the youth justice system, rates of custodial sentences and rates of re-offending.

- First time entrants into the youth justice system - A reduction of $26 \%$

- Custodial sentences - A reduction of $43.3 \%$

- Rates of re-offending - A reduction of $2 \%$ in the proportion reoffending; a reduction in numbers of reoffences of $6.6 \%$

Figure 22 below shows the local key result area outcomes against the core city averages in 2012/2013, which shows that Bristol performed better than core city averages in all areas: 


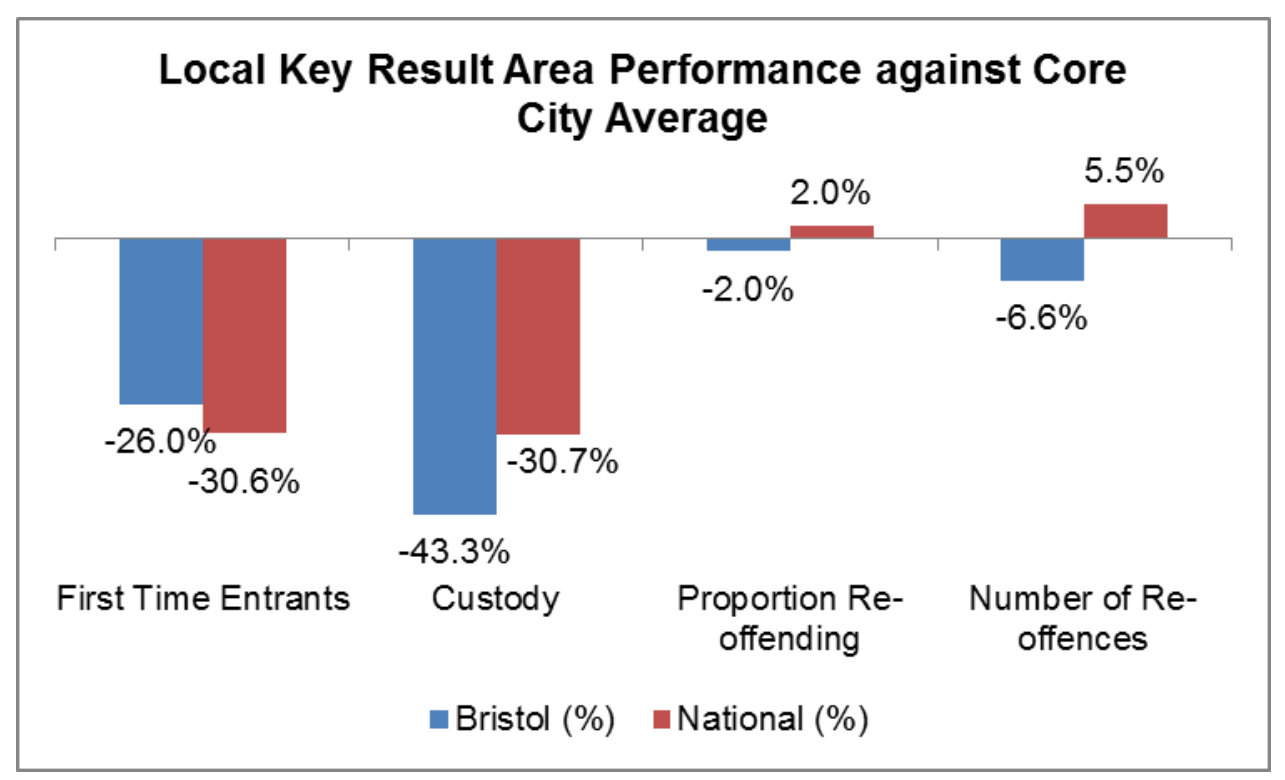

Figure 22: Local Key Result Area Performance against Core City Average

Caseloads supervised by the YOT have reduced over the past four years, from a daily average snapshot caseload of 280 to 180. Some of the reduction has been mirrored in reductions in resources and staffing in the YOT. The seriousness of the caseload has increased, particularly in relation to complex needs, vulnerability and risks that the young offenders pose to themselves. The number of serious cases in relation to safeguarding issues has also trebled since 2011. Although the actual numbers reported are still relatively small, the increase reflects a broader trend in the caseload.

There has been a sharp increase in the numbers of girls and young women in the youth justice system locally, from $15 \%-20 \%$ on average in recent years, to $28 \%$ in $2012 / 2013$.

In 2012/2013, Bristol is the best performing core city in reducing re-offending. The early adoption of the integrated offender management approach, alongside the YOT multi-agency approach to managing young offenders, through a mix of enforcement and rehabilitation, has focused resources on those most likely to re-offend. In addition, since 2005 , there has been a downward trend with an average $43 \%$ reduction in the numbers of re-offences.

The reduction in full-time entrance and custody is a national trend, and there are three potential explanations for such trend:

- Shift by the Police from prosecution to using restorative solutions (youth restorative disposal). This has produced some good results, with about $18 \%$ re-offending and offers better victim satisfaction with the outcome

- The historic impact of central government funded positive prevention projects

- The demographics of the young people between 10 and 17 years population at their lowest in Bristol for more than a decade.

\section{Recommendations}

- Ensure the availability of resources for prevention and early intervention to reduce and contain the numbers of young people who go on to high cost care or custody solutions.

- Ensure that planning over the next three years is in place to meet the demographic challenge and the likely increased demands on the system that will follow. 


\section{Glossary of Terms}

\begin{tabular}{|c|c|}
\hline Acronym & Name \\
\hline ABC & Acceptable Behaviour Contract \\
\hline A\&E & Accident and Emergency \\
\hline ASB & Anti-social Behaviour \\
\hline ASPT & Avon \& Somerset Probation Trust \\
\hline BID & Business Improvement District \\
\hline BME & Black and Minority Ethnic \\
\hline CAADA & Co-ordinated Action Against Domestic Abuse \\
\hline Channel & Multi-agency approach to protect people at risk from radicalisation \\
\hline CJIT & Criminal Justice Intervention Team \\
\hline CPS & Crown Prosecution Service \\
\hline CYPS & Children and Young People Services \\
\hline DASH & Risk Identification Checklist for Domestic Violence, Stalking and Honour-based Violence \\
\hline DBO & Drinking Banning Orders \\
\hline DIP & Drug Intervention Programme \\
\hline EDL & English Defence League \\
\hline EIS & Early Intervention Service \\
\hline FGM & Female Genital Mutilation \\
\hline GPS & Global Positioning System \\
\hline HIV & Human Immunodeficiency Virus \\
\hline IDAP & Integrated Domestic Abuse Programme \\
\hline IDVA & Independent Domestic Violence Advisors \\
\hline IMPACT & $\begin{array}{l}\text { Integrated offender management project which manages offenders responsible for acquisitive } \\
\text { crime }\end{array}$ \\
\hline IOM & Integrated Offender Management \\
\hline IRiS & Integrated Response, Integrated Service \\
\hline ISVA & Independent Sexual Violence Advisor \\
\hline JSA & Jobseeker's Allowance \\
\hline LAPE & Local Alcohol Profiles for England \\
\hline LGBT & Lesbian, Gay, Bisexual and Transgender \\
\hline LSOA & Lower Super Output Area \\
\hline MARAC & Multi Agency Risk Assessment Conferences \\
\hline NDT & Neighbourhood Delivery Team \\
\hline NHS & National Health Service \\
\hline NOCUs & Non Opiate or Crack users \\
\hline NPA & Neighbourhood Policing Area \\
\hline NRM & National Referral Mechanism \\
\hline OCUs & Opiate and/or crack users \\
\hline PCC & Police and Crime Commissioner \\
\hline PREVENT & Prevent is one of the four strands of CONTEST, the UK strategy for countering terrorism \\
\hline PTSD & Post-traumatic stress disorder \\
\hline QOL & Quality of Life Survey \\
\hline ROADS & Recovery Orientated Alcohol and Drug Service \\
\hline SARC & Sexual Assault Referral Centre \\
\hline SPAHC & Strategic Partnership against Hate Crime \\
\hline SSO & Serious Sexual Offences \\
\hline
\end{tabular}




\begin{tabular}{ll}
\hline SSWOP & Street Sex Work Options Project \\
SUSG & Service User Strategic Group (for hate crime) \\
TMG & Tension Monitoring Group \\
UKHTC & United Kingdom Human Trafficking Centre \\
UWE & University of the West of England, Bristol \\
VAAWG & Violence against Women and Girls \\
VAP & Violence against the Person \\
VCS & Voluntary and Community Sector organisations \\
WRAP & Workshop to Raise Awareness of Prevent \\
YOT & Youth Offending Team \\
\hline
\end{tabular}




\section{Bibliography}

1. Avon \& Somerset Neighbourhood Statistics, Recorded Crime Performance \& Crime for Bristol (2013)

2. Avon and Somerset Police and Crime Needs Assessment (Working Document, October, 2013).

3. Bristol City Council, '2011 Census First Release - Bristol City Council Analysis', available at: http://www.bristol.gov.uk/sites/default/files/documents/council and democracy/statistics and census infor mation/2011\%20Census\%20First\%20Release\%20-\%20Bristol\%20City\%20Council\%20Analysis.pdf

4. Bristol City Council, 'Neighbourhood Partnership Statistical Profiles', available at: http://www.bristol.gov.uk/page/council-and-democracy/neighbourhood-partnership-statistical-profiles

5. Bristol City Council, 'Quality of Life in Bristol 2012' (March 2013).

6. Bristol Community Cohesion Statistics (June 2013).

7. Bristol Hate Crime Needs Assessment 2010/2011 (2011).

8. Bristol Reducing Re-offending Plan 2013/2014 (2013)

9. Centre for Problem Orientated Policing, 'Stolen Goods Markets' (March 2012).

10. Chainey. S., 'Phase 2: Understanding Mobile Phone Theft in the Core Cities (2013).

11. Crime Survey for England and Wales (December 2012).

12. HM Government, 'Challenge It, Report It, Stop It: The Government's Plan to Tackle Hate Crime' (2012), available at: https://www.gov.uk/government/uploads/system/uploads/attachment data/file/97849/actionplan.pdf

13. Home Office Circular 003/2013, 'Circular: New Government Domestic Violence and Abuse Definition' (2013)

14. Home Office, 'Tackling Theft with the Market Reduction Approach' (2002).

15. Home Office, Stop and Search: https://www.gov.uk/government/consultations/stop-and-search (accessed: $20^{\text {th }}$ September 2013).

16. Local Alcohol Profiles for England (LAPE) (2013).

17. Ministry of Justice, 'Legal Aid Reform': https://www.nomisweb.co.uk/reports//mp/la/2038431894/subreports/ccadr time series/report.aspx

18. Ministry of Justice, 'Local Offending Statistics' (2013).

19. NTA, ‘Drug Treatment Value for Money Tool - Summary Report' (2012).

20. Porter, K., 'Alcohol Strategic Needs Assessment':

http://www.bristol.gov.uk/sites/default/files/documents/community and safety/safer bristol/Alcohol\%20Stra tegic\%20Needs\%20Assessment\%202012\%20final.pdf

21. 'Rehabilitation of Hate Crime Offenders' (2011), available at: http://www.niacro.co.uk/filestore/documents/Rehabilitation\%20of\%20Hate\%20Crime\%20OffendersEquality\%20\&\%20Human\%20Rights\%20Commission\%20Scotland-Spring\%202011.pdf

22. 'Setting the Record' (2012). 
23. Safer Bristol Partnership, 'Commissioning a Recovery Orientated Substance Misuse Treatment System for Bristol - Commissioning Strategy 2012 - 2015':

http://www.bristol.gov.uk/sites/default/files/documents/community and safety/safer bristol/Commissioning \%20a\%20Recovery\%200rientated\%20Substance\%20Misuse\%20Treatment\%20System\%20for\%20Bristol \%20Commissioning\%20Strategy\%202012\%20-\%202015.pdf

24. Schools Health Unit Report (2011).

25. Sutton, M., 'How Prolific Thieves Sell Stolen Goods: Describing, Understanding and Tackling the Local Markets in Mansfield and Nottingham', Internet Journal of Criminology (2008).

26. The Centre for Social Justice, 'It Happens Here - Equipping the United Kingdom to Fight Modern Slavery': http://www.centreforsocialjustice.org.uk/UserStorage/pdf/Pdf\%20reports/CSJ Slavery Full Report WEB(5 ..pdf

27. Trevillion, K. et al, 'Experiences of Domestic Violence and Mental Disorder: A Systematic Review and Meta-Analysis', available at: http://www.plosone.org/article/info\%3Adoi\%2F10.1371\%2Fjournal.pone.0051740

28. University College London (UCL) Jill Dando Institute of Security and Crime Science (2013).

29. User Guide to Home Office Crime Statistics (October 2011).

30. 'Victims of Trafficking at Risk Over NHS Charging Plan', available at: http://www.independent.co.uk/news/uk/politics/victims-of-sex-trafficking-at-risk-over-nhs-charging-plans$\underline{8688788 . h t m l}$

31. Walby, S., 'Costs for Domestic Violence Per Local Area', available at: http://www.avaproject.org.uk/media/60461/costs\%20of\%20dv\%20by\%20local\%20authority.pdf 
To find out more about Safer Bristol or this document, please contact:

Safer Bristol Partnership

Princess House

Princess Street

Bedminster

Bristol BS3 4AG

Tel: 01179142222

Email: safer@bristol.gov.uk

Website: www.saferbristol.org.uk

You can also view the accessible format of this report from our website, http://www.bristol.gov.uk/page/safer-bristol, or by contacting us using the contact details above 